OPEN ACCESS

Edited by: Luc Van Kaer, Vanderbilt University, United States

Reviewed by: Lucia Mori,

Universität Basel, Switzerland Dominic Paquin Proulx, United States Military HIV Research Program, United States

*Correspondence: Lucy C. Garner lucy.garner@merton.ox.ac.uk; Nicholas M. Provine nicholas.provine@ndm.ox.ac.uk

Specialty section: This article was submitted to T Cell Biology, a section of the journal

Frontiers in Immunology

Received: 10 May 2018 Accepted: 14 June 2018 Published: 28 June 2018

Citation: Garner LC, Klenerman P and Provine NM (2018) Insights Into Mucosal-Associated Invariant $T$ Cell Biology From Studies of Invariant Natural Killer T Cells.

Front. Immunol. 9:1478. doi: 10.3389/fimmu.2018.01478

\section{Insights Into Mucosal-Associated Invariant T Cell Biology From Studies of Invariant Natural Killer T Cells}

\author{
Lucy C. Garner ${ }^{1 *}$, Paul Klenerman ${ }^{1,2}$ and Nicholas M. Provine ${ }^{1 *}$ \\ ${ }^{1}$ Translational Gastroenterology Unit, Nuffield Department of Medicine, University of Oxford, Oxford, United Kingdom, \\ ${ }^{2}$ Peter Medawar Building for Pathogen Research, University of Oxford, Oxford, United Kingdom
}

Mucosal-associated invariant T (MAIT) cells and invariant natural killer T (iNKT) cells are innate-like $T$ cells that function at the interface between innate and adaptive immunity. They express semi-invariant $T$ cell receptors (TCRs) and recognize unconventional non-peptide ligands bound to the MHC Class I-like molecules MR1 and CD1d, respectively. MAIT cells and iNKT cells exhibit an effector-memory phenotype and are enriched within the liver and at mucosal sites. In humans, MAIT cell frequencies dwarf those of iNKT cells, while in laboratory mouse strains the opposite is true. Upon activation via TCR- or cytokine-dependent pathways, MAIT cells and iNKT cells rapidly produce cytokines and show direct cytotoxic activity. Consequently, they are essential for effective immunity, and alterations in their frequency and function are associated with numerous infectious, inflammatory, and malignant diseases. Due to their abundance in mice and the earlier development of reagents, iNKT cells have been more extensively studied than MAIT cells. This has led to the routine use of iNKT cells as a reference population for the study of MAIT cells, and such an approach has proven very fruitful. However, MAIT cells and $\mathrm{iNKT}$ cells show important phenotypic, functional, and developmental differences that are often overlooked. With the recent availability of new tools, most importantly MR1 tetramers, it is now possible to directly study MAIT cells to understand their biology. Therefore, it is timely to compare the phenotype, development, and function of MAIT cells and iNKT cells. In this review, we highlight key areas where MAIT cells show similarity or difference to iNKT cells. In addition, we discuss important avenues for future research within the MAIT cell field, especially where comparison to iNKT cells has proven less informative.

\footnotetext{
Keywords: mucosal-associated invariant T cells, natural killer T cells, innate-like T cells, phenotype, development, activation, effector function, subsets
}

\section{INTRODUCTION}

Mucosal-associated invariant T (MAIT) cells and invariant natural killer T (iNKT) cells are two populations of innate-like T cells that have emerged in recent years as crucial players in the development and maintenance of immunity. This is demonstrated by the array of infectious, inflammatory, and malignant diseases in which they have been implicated and in which they play diverse roles $(1-5)$. Depending on the nature of the infectious or inflammatory setting, these can range from host protective functions, for example, antimicrobial or antitumor responses, to the augmentation of disease (1-5). 
Mucosal-associated invariant T cells and iNKT cells function at the bridge between innate and adaptive immunity. While they express a T cell receptor (TCR), similar to conventional T cells of the adaptive immune system, their TCRs are semi-invariant and recognize a limited range of non-peptide ligands presented by monomorphic MHC-like molecules $(6,7)$. Consequently, the TCRs of MAIT cells and iNKT cells may function in a manner more akin to that of the pattern-recognition receptors expressed on innate immune cells, for example, macrophages and dendritic cells (DCs). Furthermore, MAIT cells and iNKT cells display an effector-memory phenotype prior to antigen exposure, can be activated by cytokines independent of their TCR, and can rapidly exert their effector functions upon activation without the requirement for clonal expansion, properties more analogous to innate immune cell types $(8,9)$. Given these distinctive characteristics, they are likely to play particularly important roles during the early stages of an immune response, prior to the differentiation of conventional effector T cells.

Although MAIT cells and iNKT cells exhibit many similarities, they also show important differences that are often disregarded. For instance, MAIT cells are the largest subset of donor-unrestricted $\mathrm{T}$ cells in humans, and their frequency in peripheral blood and certain tissues can be more than 100-fold greater than that of iNKT cells, whereas in mice iNKT cells are the more abundant population in most tissues $(10,11)$. Moreover, while MAIT cells in humans form a homogeneous population with mixed Th1/Th17 functionality, iNKT cells are highly diverse and can be divided into functionally distinct subsets $(5,11)$.

Given their much higher frequency in mice and the earlier availability of tetramers for their specific identification, iNKT cells have been more widely studied than MAIT cells. Furthermore, because of the similarities in their phenotypes, findings from the iNKT cell field have often been assumed to also apply to MAIT cells. With the discovery of MAIT cell ligands and the recent generation of tetramers for accurate MAIT cell identification (7, $12,13)$, it is timely to consider the phenotype, development, and function of MAIT cells, how this relates to iNKT cells, and where gaps remain in our understanding. This review will focus on key areas of similarity and difference between MAIT cells and iNKT cells and will highlight important remaining questions in the MAIT cell field, many of which should now be feasible to address using the newly available tetramers.

\section{KEY CHARACTERISTICS}

\section{Frequency and Localization}

Mucosal-associated invariant $\mathrm{T}$ cells represent a relatively large population of lymphocytes in humans, comprising up to $10 \%$ of peripheral blood T cells (14). iNKT cells are comparatively rare, with an average frequency of around $0.1 \%$ of $\mathrm{T}$ cells, although both MAIT and iNKT cell frequencies are highly variable between individuals (15-17). Interestingly, iNKT cells are far more abundant than MAIT cells in mice $(18,19)$.

Mucosal-associated invariant T cells preferentially localize to peripheral tissues (11), analogous to iNKT cells (10). In humans, MAIT cells are particularly enriched in the liver $(5-50 \%$ of
T cells) and are also abundant in adipose tissue, in the lung, in the female genital tract, and to varying degrees in the gut, while their frequency is low in peripheral lymph nodes (12, 14, 20-26). MAIT cells and iNKT cells in mice show a largely similar tissue distribution to human MAIT cells, with enrichment in the liver and lung $(18,19)$. Due to their low abundance, the tissue distribution of human iNKT cells remains poorly characterized, although they are particularly enriched in adipose tissue (27), comparable to human MAIT cells (20).

Evidence from parabiosis studies in mice suggests that iNKT cells comprise predominantly tissue-resident populations that do not recirculate, in contrast to conventional $\mathrm{CD} 4^{+}$and $\mathrm{CD} 8^{+}$ T cells $(28,29)$. The capacity of tissue MAIT cells to recirculate has not yet been examined. In support of a tissue-resident phenotype, MAIT cells lack expression of the lymph node homing receptors CD62L and CCR7 (14) and express tissue-resident T cell markers in mucosal tissue, including CD69, CD103, and CRTAM (25, 30). In addition, human liver MAIT cells express LFA-1 (31), a molecule that is required for retention of liver iNKT cells in mice (28). MAIT cells accumulate in the lungs of mice following intranasal infection with Salmonella enterica serovar Typhimurium and remain in situ for at least 7 weeks post-infection, implying long-term retention in tissues (32). Finally, MAIT cells express the transcription factor PLZF (33), and conventional CD4 ${ }^{+} \mathrm{T}$ cells in mice acquire a tissue-resident phenotype following ectopic expression of PLZF (28). However, CCR7-CD103- MAIT cells have recently been identified in human thoracic duct lymph at a similar frequency to that in peripheral blood (34). As CCR7 is required for lymph node entry, the authors suggest that MAIT cells in the lymph must have exited from non-lymphoid tissues. Based on these findings, it is possible that tissue MAIT cells comprise largely resident populations, while MAIT cells in certain tissues and/or particular subsets, are capable of recirculation. Such a model would need to be tested in mouse parabiosis experiments.

In mice, MAIT cell frequency is under considerable genetic control. MAIT cells show differential abundance in different strains of mice (19), and increased MAIT cell numbers in CAST/ EiJ mice can be mapped to a single genetic locus (35). Similarly, iNKT cell frequency is strongly regulated by genetic factors, as indicated by longitudinal and twin studies in humans, and analyses of iNKT cell frequency in different wild-type and congenic mouse strains (36-40). In addition to genetics, MAIT cell frequency is influenced by a number of environmental factors. Their frequency decreases in the blood with age (after $\sim 25$ years old) and in numerous diseases, while they expand in certain tissues upon infection or inflammation $(3,32,41-44)$, comparable to iNKT cells (10, 45,46 ). Moreover, the frequency of $\mathrm{V} \alpha 7 \cdot 2^{+} \mathrm{CD} 161^{\text {hi }} \mathrm{T}$ cells (a proxy for MAIT cell frequency) shows no correlation in human mothers and neonates, and the correlation in $\mathrm{V} \alpha 7.2^{+} \mathrm{CD} 161^{\mathrm{hi}}$ $\mathrm{T}$ cell frequency at birth is equally high in monozygotic and dizygotic twins (47). This suggests that environmental factors may dominate over genetic factors in regulating MAIT cell frequency in humans. However, these findings need to be confirmed using the MR1/5-OP-RU [5-(2-oxopropylideneamino)-6-Dribitylaminouracil] tetramer for MAIT cell identification, as MR1/5-OP-RU tetramer ${ }^{+}$MAIT cells comprise only a small fraction $(<20 \%)$ of $\mathrm{V} \alpha 7.2^{+} \mathrm{CD} 161^{\text {hi }} \mathrm{T}$ cells at birth, in contrast to 
adults, where $\mathrm{V} \alpha 7.2^{+} \mathrm{CD} 161^{\text {hi }} \mathrm{T}$ cells are typically $>95 \% \mathrm{MR} 1 / 5-$ OP-RU tetramer ${ }^{+}$(47). Therefore, further research is required to establish the relative role of genetic and environmental factors in regulating MAIT cell frequency in mice and humans.

\section{TCR Usage}

The semi-invariant $\alpha \beta$ TCRs of MAIT cells and iNKT cells comprise a largely invariant TCR $\alpha$ chain paired with a biased repertoire of $\mathrm{V} \beta$ chains. In humans, MAIT cells express a V $\alpha 7.2$ J $\alpha 33 / 12 / 20$ (TRAV1-2/TRAJ33/12/20) TCR $\alpha$ chain preferentially paired with V $\beta 2$ or V $\beta 13$ (TRBV20 or TRBV6) (12, 48-50), while the iNKT TCR comprises a V $\alpha 24-J \alpha 18$ (TRAV10/TRAJ18) TCR $\alpha$ chain paired exclusively with V $\beta 11$ (TRBV25) (Table 1) (48, 51, 52). Conventional $\mathrm{T}$ cells recognize short peptide antigens presented by highly polymorphic MHC Class I or MHC Class II molecules. By contrast, MAIT cells and iNKT cells recognize non-peptide ligands bound to monomorphic MHC Class I-like molecules, namely riboflavin metabolites bound to $\operatorname{MR} 1(7,13$, 22), and glycolipid/phospholipid antigens bound to CD1d (6), respectively (Table $\mathbf{1}$ ).

\section{Phenotype}

In humans, MAIT cells are predominantly CD8 ${ }^{+}$(70-90\%), with some $\mathrm{CD}^{-} \mathrm{CD}^{-}$(DN) $(10-20 \%)$, and a minor population of CD $4^{+}$cells (Table 1) $(12,16,43)$. iNKT cells can also be CD ${ }^{+}$ (absent in mice), DN, or CD4 ${ }^{+}$(Table 1) $(60-62,98,99)$. Within the CD8-expressing subset, both MAIT cells and iNKT cells predominantly express $\mathrm{CD} 8 \alpha \alpha$ homodimers or are $\mathrm{CD} 8 \alpha^{+} \beta^{\text {low }}$ (Table 1) (12, 61-63), in contrast to conventional T cell populations that are mainly CD $8 \alpha \beta^{+}(>90 \%)$. CD $8 \alpha \alpha$ homodimers might function to inhibit $\mathrm{T}$ cell activation, although their physiological role remains poorly defined (100).

Human MAIT cells display an effector-memory phenotype and characteristic expression of several surface molecules (CD161, CD26), cytokine and chemokine receptors (IL-18R $\alpha$, CCR5, CCR6), and transcription factors (PLZF, ROR $\gamma$ t, T-bet) (Table 1) (11). As their phenotype is largely homogeneous and MR1 tetramers have only recently been developed, human MAIT cells are routinely identified using surrogate markers, most commonly as $\mathrm{V} \alpha 7.2^{+} \mathrm{CD} 161^{\text {hi }} \mathrm{T}$ cells, but also using V $\alpha 7.2$ combined with IL-18R $\alpha$ or CD26. In contrast to the homogeneity of MAIT cells, iNKT cells show considerable heterogeneity and thus must be directly identified using CD1d/ $\alpha$-galactosylceramide ( $\alpha$ GalCer) tetramers or with an antibody to the invariant V $\alpha 24-J \alpha 18$ TCR $\alpha$ chain in humans. While $\mathrm{CD}^{+}$and $\mathrm{CD}^{-}{ }^{-}$iNKT cell populations show disparate expression of memory markers, chemokine receptors, and natural killer (NK) cell receptors $(62,65,84)$, the predominant $\mathrm{CD}^{-}$population shows resemblance to MAIT cells, displaying an effector-memory phenotype and similar expression of surface receptors (Table 1) $(65,84,101)$. Human MAIT cells coexpress the transcription factors PLZF, T-bet, and ROR $\gamma \mathrm{t}$ (91, 102), whereas their expression is subset specific for mouse MAIT cells, with cells expressing PLZF and either T-bet or ROR $\gamma \mathrm{t}$ (Table 1) $(19,102)$. This dichotomous expression of T-bet and ROR $\gamma t$ is also seen in mouse iNKT cells (Table 1) (86). Therefore, the expression of a mixed Th1/Th17 transcription factor profile appears unique to human MAIT cells.
In summary, MAIT cells and iNKT cells show many overlapping characteristics, including expression of semi-invariant TCRs, recognition of non-peptide ligands, and an innate-like effectormemory phenotype. However, the phenotype of iNKT cells is considerably more heterogeneous than that of MAIT cells. MAIT cells and iNKT cells predominantly localize to peripheral tissues under homeostatic conditions, especially the liver and mucosal tissues, and are therefore optimally positioned to act as a first line of defense at the site of microbial infection.

\section{MOUSE MODELS}

\section{TCR Transgenic}

Transgenic mouse models are widely used to study the phenotype and function of MAIT cells and iNKT cells, and their role in different disease settings. While use of these models has provided major contributions to our understanding of both cell subsets, it is also important to be aware of their limitations.

Mice that constitutively express the MAIT and iNKT cell invariant TCR $\alpha$ chain, namely, $\mathrm{V} \alpha 19$-J $\alpha 33$ (termed $\mathrm{iV} \alpha 19$ in several studies) $(16,103,104)$ and $\mathrm{V} \alpha 14-\mathrm{J} \alpha 18$ (V $\alpha 14-\mathrm{J} \alpha 281$ nomenclature used in early studies) $(105,106)$, respectively, have been generated on a $\mathrm{C}^{-/-}$background. As intended, these mice have an increased frequency of the target cell population. However, as is commonly observed in TCR $\alpha$ transgenic models, normal $\mathrm{T}$ cell development is dysregulated. TCR diversity is greatly reduced, $\mathrm{T}$ cell numbers are significantly decreased in the thymus and many peripheral tissues, and the mice harbor an expanded population of DN T cells. In addition, as mice overexpressing the MAIT or iNKT invariant TCR $\alpha$ chains also harbor other T cell populations (16, 103-105), comparison of mice deficient and sufficient in MR1 or CD1d, respectively, is necessary in order to identify features specific to the cell subset of interest.

Along with global changes in T cell development, MAIT cells and iNKT cells from TCR $\alpha$ transgenic mice exhibit certain differences in their phenotype, function, subset distribution, and tissue localization compared with their wild-type counterparts. For example, MAIT cells from iV $\alpha 19$ TCR $\alpha$ transgenic mice display a naïve phenotype, lack expression of PLZF, and secrete considerable amounts of IL-10 and Th2 cytokines $(16,103,104)$, in contrast with MAIT cells from wild-type mice (19). Moreover, while wild-type iNKT cells produce both IL- 4 and IFN- $\gamma$, T cells from V $\alpha 14-\mathrm{J} \alpha 18$ TCR $\alpha$ transgenic mice produce high levels of IL-4, but little IFN- $\gamma$ following stimulation with $\alpha \mathrm{CD} 3$ (105). However, several groups have generated refined V $\alpha 14-\mathrm{J} \alpha 18$ TCR $\alpha$ mouse models using somatic cell nuclear transfer (107) or induced pluripotent stem cells (108), in which iNKT cells can secrete high levels of both IL-4 and IFN- $\gamma$.

$\mathrm{V} \beta$ transgenic mice, for example, $\mathrm{V} \beta 6$ and $\mathrm{V} \beta 8$ transgenic mice, can be studied as an alternative to TCR $\alpha$ transgenics or can be crossed with TCR $\alpha$ transgenics to further increase MAIT or iNKT cell frequency, and to decrease unwanted TCR specificities $(16,109)$. An important limitation of these models is that, as MAIT and iNKT cell populations utilize multiple TCR $\beta$ chains, the forced usage of a single $\mathrm{V} \beta$ will bias the antigen specificity, and thereby the functionality of the generated population. In addition to the 
TABLE 1 | Characteristics of human and mouse mucosal-associated invariant T (MAIT) and invariant natural killer T (iNKT) cells.

\begin{tabular}{|c|c|c|c|c|c|c|c|c|c|}
\hline & $\begin{array}{l}\text { T cell receptor (TCR) } \\
\text { usage }\end{array}$ & $\begin{array}{l}\text { MHC-like } \\
\text { molecule }\end{array}$ & Ligands & CD4/CD8 & $\begin{array}{l}\text { Naïve/ } \\
\text { memory }\end{array}$ & Chemokine receptors & $\begin{array}{l}\text { Cytokine } \\
\text { receptors }\end{array}$ & $\begin{array}{l}\text { Cytokines } \\
\text { produced }\end{array}$ & $\begin{array}{l}\text { Transcription } \\
\text { factors }\end{array}$ \\
\hline $\begin{array}{l}\text { Human } \\
\text { MAIT }\end{array}$ & $\begin{array}{l}\text { V } \alpha 7.2-J \alpha 33 / 12 / 20 \\
\text { (TRAV1-2/TRAJ33/12/20) } \\
\text { TCR } \alpha . \text { Biased repertoire } \\
\text { of } \vee \beta \text { chains - V } \beta 2 \text {, } \\
\text { V } \beta 13 \text { (TRBV20, TRBV6). } \\
\text { Oligoclonal CDR3 } \beta\end{array}$ & MR1 & $\begin{array}{l}\text { Activating - riboflavin metabolites } \\
\text { (5-OP-RU, 5-OE-RU), drug } \\
\text { metabolites (e.g., diclofenac } \\
\text { metabolites). Inhibitory - folic acid } \\
\text { metabolites (6-FP, Ac-6-FP), small } \\
\text { organic molecules } \\
\text { (e.g., salicyclates) }\end{array}$ & $\begin{array}{l}70-85 \% \mathrm{CD}^{+}(\sim 50 \% \\
\mathrm{CD} 8 \alpha^{+} \alpha^{+}, \sim 50 \% \\
\left.\mathrm{CD} 8 \alpha^{+} \beta^{+}\right), 10-20 \% \\
\mathrm{DN},<5 \% \mathrm{CD} 4^{+}\end{array}$ & $\begin{array}{l}\mathrm{CD} 45 \mathrm{RO}^{+} \\
\mathrm{CCR} 7^{-} \mathrm{CD} 62 \mathrm{~L}^{10} \\
\text { effector- } \\
\text { memory }\end{array}$ & $\begin{array}{l}\text { CCR2, CCR5, CCR6, } \\
\text { CXCR6 }\end{array}$ & $\begin{array}{l}\text { IL-12R, } \\
\text { IL-18R, } \\
\text { IL-7R, } \\
\text { IL-15R, } \\
\text { IL-23R }\end{array}$ & $\begin{array}{l}\text { IFN- } \gamma, \text { TNF- } \\
\alpha, \text { IL-17A, } \\
\text { MIP-1 } 1 \beta\end{array}$ & 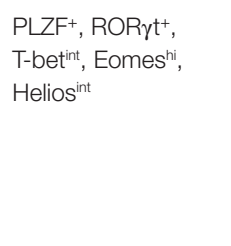 \\
\hline $\begin{array}{l}\text { Mouse } \\
\text { MAIT }\end{array}$ & $\begin{array}{l}\text { V } \alpha 19-J \alpha 33 \text { (TRAV1/TRAJ33) } \\
\text { TCR } \alpha . \text { Biased repertoire } \\
\text { of } \vee \beta \text { chains }- \text { V } \beta 6, V_{\beta} 8 \\
\text { (TRBV19, TRBV13) }\end{array}$ & MR1 & $\begin{array}{l}\text { Activating - riboflavin metabolites } \\
\text { (5-OP-RU, 5-OE-RU). Inhibitory } \\
\text { - folic acid metabolites (6-FP, Ac-6- } \\
\text { FP), small organic molecules } \\
\text { (e.g., salicyclates) }\end{array}$ & $\begin{array}{l}\text { B6 mice }-55-90 \% \\
\text { DN, }<25 \% \mathrm{CD}^{+} \\
\left(\sim 50 \% \mathrm{CD} 8 \alpha^{+} \beta^{-},\right. \\
\left.\sim 50 \% \mathrm{CD} 8 \alpha^{+} \beta^{+}\right) \\
<20 \% \mathrm{CD} 4+\text {. Variation } \\
\text { across tissues }\end{array}$ & $\begin{array}{l}\text { CD44 }{ }^{\text {hiCD }} 62 L^{10} \\
\text { effector- } \\
\text { memory }\end{array}$ & CXCR6 & $\begin{array}{l}\text { IL-18R, } \\
\text { IL-7R }\end{array}$ & $\begin{array}{l}\text { IFN- } \gamma, \text { IL-17A, } \\
\text { MIP- } 1 \alpha\end{array}$ & $\begin{array}{l}\mathrm{PLZF}^{+}, \mathrm{ROR}^{\mathrm{t}^{+}} \\
\text {(subset), T-bet+ } \\
\text { (subset) }\end{array}$ \\
\hline $\begin{array}{l}\text { Human } \\
\text { iNKT }\end{array}$ & $\begin{array}{l}\text { V } \alpha 24-J \alpha 18 \text { (TRAV10/ } \\
\text { TRAJ18), V } \beta 11 \text { (TRBV25). } \\
\text { Diverse CDR3 } \beta\end{array}$ & CD1d & $\begin{array}{l}\text { Activating - glycolipids } \\
\text { (e.g., glycosphingolipids, } \\
\text { diacylglycerols, cholesteryl } \\
\alpha \text {-glucosides) and phospholipids } \\
\text { (including lysophospholipids, } \\
\text { e.g., ether-bonded mono-alkyl } \\
\text { glycerophosphates) }\end{array}$ & $\begin{array}{l}10-100 \% \mathrm{CD}^{-} \\
\text {(average }=60 \% \\
\sim 50 \% \mathrm{CD}^{+}[>95 \% \\
\left.\mathrm{CD} 8 \alpha^{+} \alpha^{+}\right], \sim 50 \% \\
\text { DN), 0-90\% CD4 } \\
\text { (average }=40 \% \text { ) }\end{array}$ & $\begin{array}{l}\text { Predominantly } \\
\mathrm{CD}^{2} 5 \mathrm{RO}^{+} \\
\mathrm{CCR} 7{ }^{-} \mathrm{CD} 62 \mathrm{~L}^{10} \\
\text { effector- } \\
\text { memory }\end{array}$ & $\begin{array}{l}\text { Majority express CXCR3, } \\
\text { CXCR4, CCR2, CCR5. } \\
\text { Subset-specific: } \\
\text { CD4+ - CCR4. } \\
\text { CD4 } 4^{-} \text {- CXCR6, CCR6, } \\
\text { CCR1 }\end{array}$ & $\begin{array}{l}\text { IL-12R, } \\
\text { IL-18R, } \\
\text { IL-7R, } \\
\text { IL-15R }\end{array}$ & $\begin{array}{l}\text { MIP- } 1 \alpha \\
\text { MIP- } 1 \beta \\
\text { CD4 } \\
\text { TNF- }-\alpha, \text { IL }-4 \text {, } \\
\text { IL-13, IL-10, } \\
\text { GM-CSF. } \\
\text { CD4- }- \text { IFN- } \gamma \text {, } \\
\text { TNF- } \alpha\end{array}$ & $\begin{array}{l}\mathrm{PLZF}^{+}, \text {T-bet }^{+} \\
(\sim 50 \%), \text { Eomes }^{+} \\
(\sim 30 \%), \text { FoxP3 }^{+} \\
\text {(in vitro) }\end{array}$ \\
\hline $\begin{array}{l}\text { Mouse } \\
\text { iNKT }\end{array}$ & $\begin{array}{l}\text { V } \alpha 14-J \alpha 18 \text { (TRAV11/ } \\
\text { TRAJ18). Biased repertoire } \\
\text { of } \vee \beta \text { chains - V } \beta 8.2, V \beta 7 \text {, } \\
\text { V } \beta 2 \text { (TRBV13-2, TRBV29, } \\
\text { TRBV1). Diverse CDR3 } \beta\end{array}$ & CD1d & $\begin{array}{l}\text { Activating - glycolipids } \\
\text { (e.g., glycosphingolipids, } \\
\text { diacylglycerols, cholesteryl } \\
\alpha \text {-glucosides) and phospholipids } \\
\text { (including lysophospholipids, } \\
\text { e.g., ether-bonded mono-alkyl } \\
\text { glycerophosphates) }\end{array}$ & $\begin{array}{l}\text { B6 mice }-60-80 \% \\
\text { CD4+, } 20-40 \% \text { DN. } \\
\text { Variation across } \\
\text { tissues }\end{array}$ & $\begin{array}{l}\text { CD44 }{ }^{\text {hi }} \text { CD62 }{ }^{10} \\
\text { effector- } \\
\text { memory }\end{array}$ & $\begin{array}{l}\text { CXCR3, CXCR4, CXCR6, } \\
\text { CCR9 }\end{array}$ & $\begin{array}{l}\text { IL-12R, } \\
\text { IL-18R, } \\
\text { IL-7R, } \\
\text { IL-15R, } \\
\text { IL-23R }\end{array}$ & $\begin{array}{l}\text { NKT1 - IFN- } \gamma \\
\text { NKT2 - IL-4, } \\
\text { NKT17 - IL-17, } \\
\text { NKT10 - IL-10 }\end{array}$ & 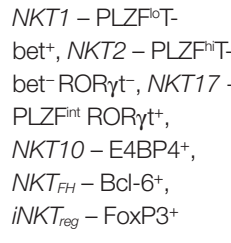 \\
\hline Reference & $(12,22,48-54)$ & $\begin{array}{l}(17,21 \\
22,55 \\
56)\end{array}$ & $(7,12,13,57-59)$ & $\begin{array}{l}(12,15,19,43 \\
60-64)\end{array}$ & $\begin{array}{l}(14,16,62 \\
65-69)\end{array}$ & $(14,19,65,70-72)$ & $\begin{array}{l}(14,17, \\
19,70 \\
73-83)\end{array}$ & $\begin{array}{l}(14,17, \\
19,50,62 \\
84-90)\end{array}$ & $\begin{array}{l}(14,19,33,86 \\
91-97)\end{array}$ \\
\hline
\end{tabular}

$D N$ - double-negative/CD4- $C D 8^{-}$ 
use of double transgenics, MAIT or iNKT cell frequency can be increased by studying transgenic mice on a $\mathrm{RAG}^{-/-}$or $\mathrm{TAP}^{-/-} \mathrm{Ii}^{-/-}$ background $(16,109)$. However, in these mice, interactions between MAIT or iNKT cells, and other conventional T cells (and $\mathrm{B}$ cells in $\mathrm{RAG}^{-/-}$mice), which might influence their phenotype and development in a wild-type setting, are completely absent.

\section{Non-Transgenic}

Given the scarcity of MAIT cells in mice and the limitations of TCR transgenic models, alternative models with increased MAIT cell frequency have been developed. A mouse strain (CAST/EiJ) with 20-fold greater frequency of MAIT cells than C57BL/6 mice was identified, and crossing these strains generated a B6-MAIT ${ }^{\text {CAST }}$ strain with increased frequencies of MAIT cells (35). These MAIT ${ }^{\text {CAST }}$ cells display a phenotype more consistent with MAIT cells from wild-type animals, including expression of PLZF, but some phenotypic and functional abnormalities remain. An alternate, non-genetic approach to increase the frequency of MAIT cells in mice is through the intranasal administration of MR1 ligand (5-OP-RU) combined with a toll-like receptor (TLR) agonist, which increases their frequency to approximately $50 \%$ of lung $\alpha \beta$ T cells (32). Further work will be required to understand how this "boosting" may impact on the phenotype and function of MAIT cells, and thereby to establish the robustness of this experimental approach. Regardless of potential current shortcomings, efforts to develop mouse models with increased MAIT cell frequencies, while avoiding the limitations of TCR transgenic systems, appear promising.

\section{MHC/TCR Knockout}

Models with reduced, rather than increased, MAIT or iNKT cell frequencies have also been generated either by altering the TCR repertoire or by removing the $\mathrm{MHC}$ molecules that are essential for MAIT or iNKT cell selection. iNKT cell-deficient J $\alpha 18^{-/-}$mice are widely used; however, a recent study showed that TCR $\alpha$ rearrangement is perturbed in the original $J \alpha 18^{-/-}$strain $(110,111)$. $\mathrm{TCR} \alpha$ rearrangements using J $\alpha$ segments upstream of $\mathrm{J} \alpha 18$ are almost completely absent, and therefore, along with other $\mathrm{T}$ cell populations, MAIT cell frequency is reduced. Consequently, lack of MAIT cells may contribute to the phenotype of J $\alpha 18^{-/-}$mice. However, newer J $\alpha 18^{-/-}$models have now been generated that exhibit a normal TCR $\alpha$ repertoire (except for the lack of J $\alpha 18$ ) (112-115), thus addressing this concern.

Mice lacking MR1 or CD1d lack MAIT cells (22) or iNKT cells (116-118), respectively. However, they also lack other MR1- or CD1d-restricted T cells. A population of MR1-restricted nonMAIT T cells was recently identified in humans (119), which if present in mice would be absent in $\mathrm{MR}^{-/-}$animals. CD1d $\mathrm{d}^{-/-}$ mice lack not only iNKT cells (type I) but also diverse (type II) NKT cells. In addition, CD1 $\mathrm{d}^{-/}$mice on the BALB/c background, and to a lesser extent the C57BL/6 background, exhibit a marked increase in the frequency of MAIT cells, which might further confound studies using these mice (102). J $\alpha 18^{-1-}$ mice have the advantage that they lack only iNKT cells. It is important to bear this in mind when using $\mathrm{MR}^{-/-}$and $\mathrm{CD} 1 \mathrm{~d}^{-/-}$mice, as any identified phenotypes may not be directly attributable to MAIT or iNKT cells, respectively.
Therefore, while transgenic mouse models enable the role of MAIT cells and iNKT cells to be interrogated in vivo in health and disease, caution is necessary when using these models. Newer models continue to be developed that aim to overcome some of the drawbacks of existing models. Nevertheless, results from any mouse model should be validated in other models to avoid findings that result from peculiarities of the chosen experimental system. Moreover, it is important to bear in mind that discoveries from mouse studies may not directly translate to humans, given the vastly different frequencies of MAIT and iNKT cells in these species, in addition to other differences, for example, in functional subsets and tissue distribution.

\section{DEVELOPMENT}

\section{Thymic Development Selection}

The earliest stages of MAIT cell development in the thymus show many similarities to the thymic development of iNKT cells. As with conventional T cells, the semi-invariant TCR of MAIT cells is generated via random recombination $(49,120)$; however, its formation requires an extended $\mathrm{CD}^{+} \mathrm{CD}^{+}(\mathrm{DP})$ thymocyte lifespan. Initial rearrangement of the TCR $\alpha$ locus utilizes $3^{\prime} \mathrm{V} \alpha$ and $5^{\prime}$ J $\alpha$ segments, with later rearrangements using progressively more $5^{\prime} \mathrm{V} \alpha$ segments and more $3^{\prime} \mathrm{J} \alpha$ segments (termed proximal to distal rearrangement) $(121,122)$. Thus, formation of the MAIT cell semi-invariant TCR that incorporates the $5^{\prime}$ most $\mathrm{V} \alpha$ segment (TRAV1-2) occurs late in the lifespan of DP thymocytes. A long DP thymocyte half-life is likewise necessary for generation of the iNKT TCR and hence for iNKT cell development. iNKT cells are absent in Rorc $^{-l-}$ mice (ROR $\gamma$ t-deficient) that show a reduced DP thymocyte lifespan, but their development is rescued upon expression of the rearranged V $\alpha 14-\mathrm{J} \alpha 18$ TCR $\alpha$ chain or the antiapoptotic protein $\mathrm{Bcl}-\mathrm{xL}(123,124)$. In peripheral blood $\mathrm{T}$ cells from $R O R C^{-/-}$patients, $5^{\prime} \mathrm{V} \alpha-3^{\prime} \mathrm{J} \alpha \mathrm{TCR} \alpha$ pairings are absent, and hence these patients lack both MAIT cells and iNKT cells (125), presumably due to lack of rearrangement of their characteristic TCR $\alpha$ chains at the DP thymocyte stage.

Following TCR expression, conventional T cells undergo positive selection on cortical thymic epithelial cells that present self-peptides on MHC Class I and MHC Class II. By contrast, MAIT cells are selected by MR1-expressing DP thymocytes (126, 127), comparable to the CD1d-dependent selection of iNKT cells $(128,129)$ (Figure 1A). For iNKT cells, selection is dependent on the presentation of endogenous lipid antigens by CD1d (Figure 1A) (130). Based on this paradigm and circumstantial evidence $(131,132)$, it is highly plausible that MAIT cell selection also involves an endogenous ligand(s), although such ligands have yet to be identified.

Conventional $\mathrm{T}$ cells are positively selected in the thymus when their TCR exhibits moderate affinity for MHC/self-peptide, while thymocytes expressing high affinity TCRs are removed from the repertoire. The strength of the TCR-MR1/ligand interaction required for MAIT cell positive selection has not been investigated, but agonist selection is hypothesized based on the following information. First, a number of unconventional $\mathrm{T}$ cell 


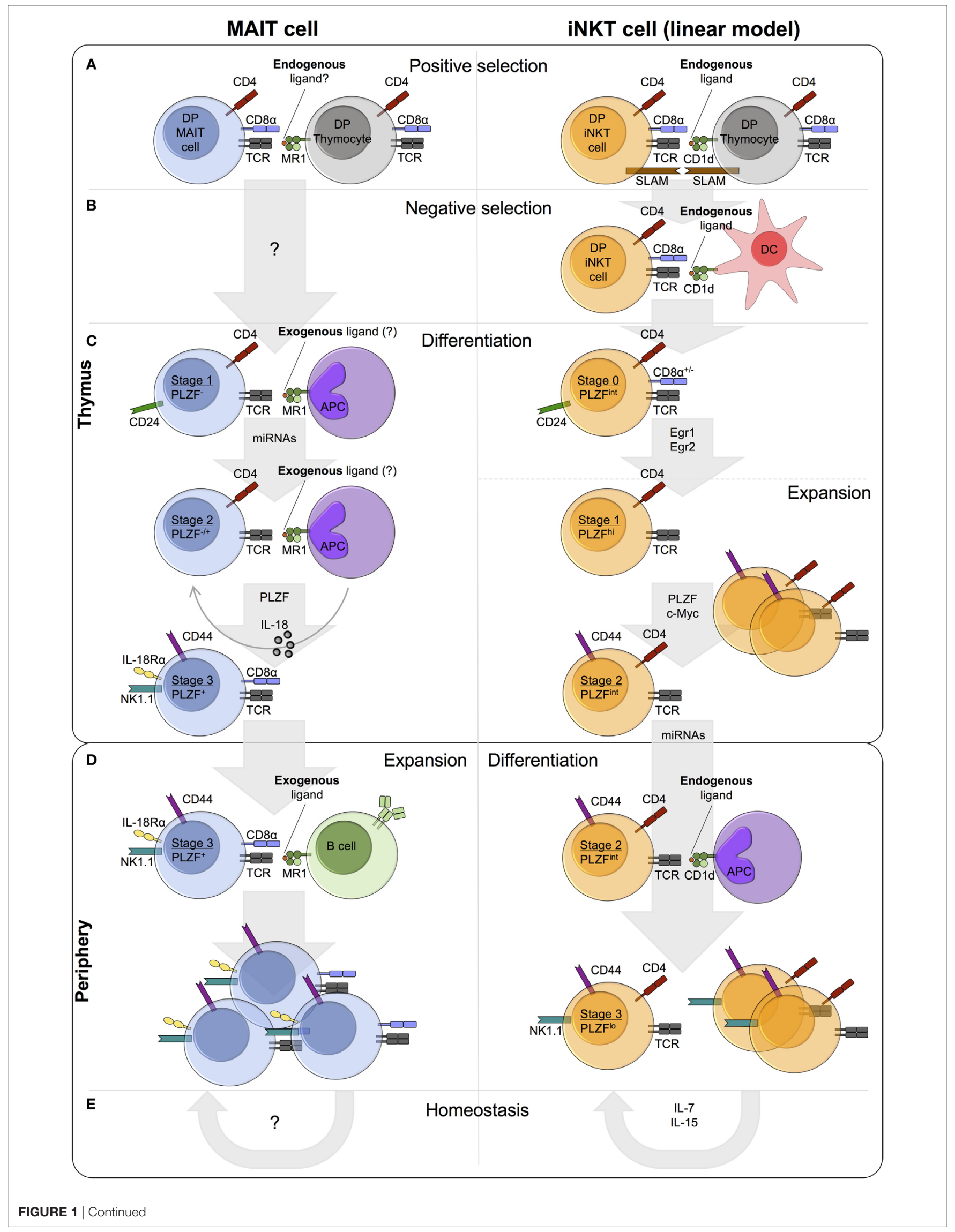


FIGURE 1 | Comparison of mucosal-associated invariant T (MAIT) cell and invariant natural killer T (iNKT) cell thymic and peripheral development in mice. (A) MAIT cells and iNKT cells are positively selected by MR1- and CD1d-expressing DP (double-positive/CD4 ${ }^{+} \mathrm{CD} 8^{+}$) thymocytes, respectively. iNKT cell positive selection involves an endogenous ligand(s). A similar role for endogenous ligand(s) in MAIT cell selection is postulated, but such ligands have yet to be identified. Concomitant with T cell receptor (TCR)-MHC-lb/ligand binding, homotypic interactions between signaling lymphocyte activation molecule (SLAM) family receptors are essential for iNKT cell, but not MAIT cell, development. (B) iNKT cells also undergo negative selection, while negative selection has not been studied for MAIT cells. (C) Following selection, MAIT and iNKT thymocytes differentiate through similar stages defined by the expression of CD24 and CD44. Stage 1 and stage 2 iNKT thymocytes are highly proliferative, whereas the proliferative capacity of thymic MAIT cells is currently unknown. A number of shared factors are required for thymic differentiation, including microRNAs (miRNAs) and PLZF, but the requirement for IL-18 and exogenous ligand (from commensal bacteria) is specific to MAIT cells. Conversely, the transcription factors Egr1, Egr2, and c-Myc have been implicated in iNKT cell development, but not investigated in MAIT cell development. iNKT cells express PLZF and exhibit effector functions at stage 1, while MAIT cells acquire effector capacity at stage 3. (D) MAIT cells and iNKT cells exit the thymus with a CD24-CD44+ memory phenotype. In the periphery, MAIT cells undergo expansion, probably driven by the presentation of exogenous ligands from commensal bacteria, whereas iNKT cell frequency remains relatively constant. (E) iNKT cell homeostasis is predominantly regulated by cytokines, in particular IL-7 and IL-15. By contrast, the role of MR1 and cytokines in MAIT cell homeostasis is currently unknown.

lineages are selected by agonist ligands, including iNKT cells, regulatory T cells, and CD8 $\alpha \alpha$ gut intraepithelial T cells (133). Second, compared with conventional thymocytes, the high avidity interaction between the iNKT TCR and selecting glycolipids results in strong TCR signaling (134) and therefore prolonged upregulation of the TCR-induced transcription factors Egr1 and Egr2 (135). The transcription factor PLZF, encoded by Zbtb16, is a direct downstream target of Egr2 (135), and both MAIT cells and iNKT cells upregulate PLZF expression during thymic development, contrasting to conventional T cells. Finally, mouse MAIT cells upregulate CD44 expression, and mouse and human MAIT cells can acquire effector function within the thymus (102), properties of antigen-experienced conventional T cells.

MR1 is essential for MAIT cell positive selection (Figure 1A) (126). However, whether engagement of other cell surface receptors is required, is currently unknown. By contrast, homotypic interactions between at least two signaling lymphocyte activation molecule (SLAM) family members (SLAMF1 and SLAMF6) are required alongside TCR-CD1d/ligand engagement, for iNKT cell development (Figure 1A). In mixed bone marrow chimeras, the frequency of iNKT cells in Slamf1/Slamf6-deficient populations is significantly reduced compared with wild-type, with a specific defect at the transition from stage $0\left(\mathrm{CD} 24^{\mathrm{hi}}\right)$ to stage $1\left(\mathrm{CD} 24^{\mathrm{lo}}\right)(136)$. SLAMF6 costimulation has been shown to augment TCR signaling, resulting in increased Egr2 expression and consequently enhanced expression of PLZF (137). MAIT cell development is independent of SLAM receptors, as patients deficient in SLAM-associated protein, an intracellular adaptor required for SLAM signaling, lack iNKT cells but show normal numbers of MAIT cells (16).

The role of negative selection in MAIT cell development has not been investigated (Figure 1B). By contrast, although not explicitly demonstrated, highly autoreactive iNKT cells likely undergo negative selection on DCs (Figure 1B) $(138,139)$. Addition of the agonist glycolipid $\alpha$ GalCer or CD1d overexpression during iNKT cell development results in decreased iNKT cell frequency in vitro and in vivo $(138,139)$. It seems likely that high avidity self-reactive MAIT thymocytes also undergo negative selection. Alternatively, peripheral MAIT cell activation could be controlled by other mechanisms, for example, dampened TCR signaling compared with conventional T cells (85).

\section{Differentiation}

The differentiation of thymic MAIT cells following selection remains relatively unexplored. However, a recent paper by
Koay et al. identified three stages of MAIT cell development in mice and humans (102). The described developmental pathway in mice, with stages defined by the expression of CD24 and CD44 (stage $1-\mathrm{CD} 24^{+} \mathrm{CD} 44^{-}$, stage $2-\mathrm{CD} 24^{-} \mathrm{CD} 44^{-}$, stage $\left.3-\mathrm{CD} 24^{-} \mathrm{CD} 44^{+}\right)$, is remarkably similar to the linear differentiation model of iNKT cell development (Figure 1C) (130). In mice, thymic stage $1\left(\mathrm{CD} 24^{\mathrm{lo}} \mathrm{CD} 44^{\mathrm{lo}}\right)$ and stage 2 $\left(\mathrm{CD} 24^{\mathrm{lo}} \mathrm{CD} 44^{\mathrm{hi}}\right) \mathrm{iNKT}$ cells are highly proliferative (Figure 1C) (140). Intrathymic iNKT cell proliferation requires expression of the transcription factor c-Myc (141). Mouse MAIT cells accumulate in the thymus with age, and stage 3 MAIT cells are more abundant than stage 1 and stage 2 in fetal thymic organ culture (102). These data suggest that murine MAIT cells proliferate in the thymus, similar to iNKT cells, but direct measures of in vivo proliferation have not been performed. By contrast, human thymic MAIT cells are present at low frequency irrespective of age $(16,102,127)$, and T cell receptor excision circle (TREC) analysis of MAIT cells in human thymus and cord blood identified no differences in TREC concentration compared with conventional T cells (127). Whether human thymic and cord blood iNKT cells show enhanced proliferative capacity relative to conventional $\mathrm{T}$ cells is unclear, as prior studies have reported conflicting findings $(73,74)$. Thus, additional independent direct assessments of MAIT and iNKT thymocyte proliferation are needed to clarify the extent of their intrathymic proliferative capacity.

Development of MAIT cells along the linear developmental pathway requires a number of different factors, some of which are also necessary for iNKT cell development (Figure 1C). MR1 is essential at all stages of MAIT cell development in vitro, and peripheral MAIT cells are nearly absent in MR1-deficient mice $(16,19,22,102)$. Likewise, CD1d is essential for the development of iNKT cells $(116-118,142)$. In the absence of commensal bacteria and IL-18 in vivo, stage 3 MAIT cells are reduced, while the frequency (but not number) of stage 1 cells is increased $(22,102)$. Moreover, MAIT cell development beyond stage 1 requires microRNAs (miRNAs), as the abundance of stage 2 and stage 3 MAIT cells is decreased in Drosha-deficient mice (102). By contrast, PLZF is necessary only for MAIT cell maturation from stage 2 to stage 3 and for their acquisition of effector function $(19,102)$.

Invariant natural killer $\mathrm{T}$ cell development similarly requires miRNAs and PLZF $(33,92,143)$. Consistent with a shared developmental niche, MAIT cell frequency is markedly increased in 
CD1d-deficient mice on a BALB/c background, with only minor differences to wild-type on the C57BL/ 6 background, although the increase in both strains is statistically significant (102). By contrast, the number of iNKT cells in the spleen and thymus of MR1-deficient mice is similar to that of wild-type, perhaps due to the much lower frequency of MAIT cells compared with iNKT cells in these mouse strains (102). In addition, the frequency of MAIT cells and iNKT cells in humans is positively correlated in adult peripheral blood (43). Despite shared development needs, the absolute requirement for commensal bacteria appears unique to MAIT cells $(22,102)$, as iNKT cell frequency is relatively conserved in germ-free (GF) mice compared with either specific pathogen-free (SPF) mice or mice harboring a conventional microflora $(144,145)$.

Stage 3 mature MAIT cells in human thymus coexpress ROR $\gamma \mathrm{t}$ and T-bet (102). By contrast, stage 3 MAIT cells in mice comprise two subsets, namely, ROR $\gamma \mathrm{t}^{+} \mathrm{T}^{- \text {bet }^{-}}$and T-bet ${ }^{+} \mathrm{ROR} \gamma \mathrm{t}^{-}$cells (102). Analogous to MAIT cells, thymic iNKT cell subsets have not been identified in humans, while iNKT cells comprise at least three different subsets in mouse thymus, named NKT1, NKT2, and NKT17 (discussed in more detail in Section "Subsets") (86, 146, 147). It is unclear whether ROR $\gamma \mathrm{t}^{+} \mathrm{T}^{- \text {bet }^{-}}$and T-bet ${ }^{+} \mathrm{ROR} \gamma \mathrm{t}^{-}$ MAIT cells represent different developmental stages or distinct subsets derived from a shared progenitor. Recent studies suggest that iNKT cell subsets arise from a common PLZFi precursor population and represent stable lineages with distinct transcriptional and epigenetic programs (86, 146, 147). However, whether the classic developmental stages model or the newer lineage segregation model best describes iNKT cell development, remains uncertain. Moreover, the specific signals required for commitment to the different iNKT cell subsets are largely unknown, although a multitude of factors, including cytokines and transcriptional regulators, can differentially regulate NKT1, NKT2, and NKT17 development (148). It would be worth investigating whether similar factors also modulate the differentiation of thymic MAIT cell subsets.

\section{Acquisition of Innate-Like Effector Function}

Mucosal-associated invariant $\mathrm{T}$ cells can acquire innate-like effector function in the thymus and secrete cytokines upon activation (102), comparable to iNKT cells $(15,140,149,150)$. Expression of the transcription factor PLZF is necessary and sufficient to drive innate-like effector differentiation (33, 92, 151-153). In PLZF-deficient mice, MAIT and iNKT cell development is almost completely abrogated and residual cells exhibit a CD44 ${ }^{\text {lo }}$ phenotype, reduced expression of characteristic phenotypic markers, and impaired cytokine secretion $(19,33,92,102)$. In addition to direct regulation by Egr2 (135), PLZF expression is regulated by the binding of Runx 1 to a shared intronic enhancer in several innate lymphoid lineages, including iNKT cells (154). Therefore, Runx1 likely also regulates PLZF expression in MAIT cells. During thymic MAIT cell development, PLZF expression begins at stage 2 (mouse $-\mathrm{CD} 24^{-} \mathrm{CD} 44^{-}$, human $\mathrm{CD} 161^{-} \mathrm{CD} 27^{+}$) and is highest at stage 3 (mouse $-\mathrm{CD} 24^{-} \mathrm{CD} 44^{+}$, human - CD161 ${ }^{+} \mathrm{CD} 27^{\text {pos-lo }}$ ) (Figure 1C) (102). By contrast, PLZF expression is induced immediately following positive selection in iNKT cells and its expression peaks in thymic stage
1 cells $\left(\mathrm{CD} 24^{\mathrm{lo}} \mathrm{CD} 44^{\mathrm{lo}}\right)$ (Figure 1C) $(33,92,135)$. Consequently, thymic stage 1 iNKT cells can secrete cytokines upon stimulation $(140,149,150)$, while MAIT cells do not acquire this functionality until stage 3 of thymic differentiation (102).

Although they can acquire effector function within the thymus, MAIT cells in humans are typically thought to exit the thymus as naïve cells and acquire their effector-memory phenotype in the periphery $(14,16,47,63,127)$. This is supported by the naive phenotype of MAIT cells in thymus and cord blood, and their rapid acquisition of CD45RO in neonates, such that $>80 \%$ of blood MAIT cells express CD45RO by 1 month of age $(14,16,47,63,127)$. However, further studies are required to fully define exactly when and where MAIT cells acquire their effector-memory phenotype and function, given that some thymic MAIT cells express PLZF and CD45RO $(16,102,155)$. Naïve stage $2\left(\mathrm{CD} 161^{-} \mathrm{CD} 27^{+}\right)$MAIT cells were recently shown to predominate in human thymus and were found to a lesser degree in cord blood and young blood (102). Thus, the majority of MAIT cells may exit the thymus at stage 2 and undergo further maturation in the periphery, while a small population matures to stage 3 in the thymus (102). Stage 3 mature MAIT cells $\left(\mathrm{CD} 24^{-} \mathrm{CD} 44^{+}\right)$are the main population in mouse thymus (102). Therefore, contrasting to human MAIT cells, but comparable to mouse iNKT cells, mouse MAIT cells probably exit the thymus as CD $44^{+}$memory cells (140). Similarly, human iNKT cells may leave the thymus as effector-memory cells, as they already display a $\mathrm{CD}_{45 \mathrm{RO}^{+}}$memory phenotype in thymus and cord blood $(66,67,156)$.

In conclusion, thymic MAIT cell development shows many similarities to that of iNKT cells, including selection on DP thymocytes, development through similar stages post-selection, a shared requirement for developmental factors, and the possibility to acquire innate-like effector function in the thymus. However, the role of MAIT cell negative selection and the extent of their intrathymic proliferation have yet to be examined. While mouse iNKT cells and likely mouse MAIT cells exit the thymus as CD $44^{+}$ effector-memory cells, human MAIT cells appear to leave the thymus as naïve cells and acquire innate-like effector function extrathymically, although the exact timing of their thymic exit needs to be clarified. The reason for such disparity between mouse and human MAIT cells in the location of effector maturation is currently unclear.

\section{Peripheral Development \\ Changes in Abundance}

While their frequency is relatively constant in the thymus, MAIT cells undergo a large population expansion in the periphery, reminiscent of intrathymic iNKT cell expansion in mice, increasing over 100 -fold from $<0.01 \%$ of $T$ cells at birth to $1-10 \%$ of $\mathrm{T}$ cells by adulthood $(14,41-43,47,102)$. The increase in MAIT cell numbers is gradual and occurs over a number of years, although estimates for the age at which adult frequencies are reached vary between studies (6-25 years of age) (14, 41-43, $47,102)$. By contrast, peripheral iNKT cell frequencies remain relatively constant from birth to adulthood $(66,157,158)$.

Though MAIT cell thymic selection is independent of B cells (16), B cells are crucial for peripheral MAIT cell expansion in mice 
(Figure 1D). Peripheral MAIT cells are almost entirely absent in B cell-deficient mice, and transfer of B cells is sufficient to induce MAIT cell expansion in $\mathrm{iV} \alpha 19 / \mathrm{V} \beta 6 \mathrm{RAG}^{-/-}$mice $(16,22)$. Whether cognate interactions between B cells and MAIT cells are necessary for such expansion has not been established. In humans, the role of B cells remains uncertain. Treiner et al. observed a reduced frequency of MAIT cells (as measured by the presence of V $\alpha 7.2-\mathrm{J} \alpha 33 \mathrm{TCR} \alpha$ transcripts) in the blood of patients who lack B cells due to a mutation in Bruton tyrosine kinase (BTK) (22). However, only four patients were analyzed, one of which had a normal number of MAIT cells. A study of common variable immunodeficiency (CVID) provides indirect evidence against a role for B cells in regulating human MAIT cell frequency (159). Although the abundance of B cells and MAIT cells was variably decreased in CVID patients, the frequency of MAIT cells showed no correlation with that of B cells. A major confounding factor in these human studies is the increased occurrence of infections in patients with $B T K$ deficiency and CVID, which can independently modulate MAIT cell frequency. Thus, whether B cells have a role in MAIT cell expansion or at other stages of their development in humans requires further investigation. B cells are not essential for iNKT cell development, but they do play an important role in human peripheral iNKT cell homeostasis (160), as discussed below.

It is widely hypothesized that peripheral MAIT cell expansion and maturation is driven by the presentation of microbial antigens on MR1, derived from either commensal or pathogenic bacteria (Figure 1D). Although this has yet to be formally proven, a variety of evidence supports this hypothesis. In humans, MAIT cells are naive in thymus, cord blood, and in newborns, but rapidly acquire a memory phenotype in the blood during the first month of life $(14,16,47,102)$, concomitant with exposure to bacteria. MAIT cells are absent in GF mice (22) and expand upon microbial reconstitution with a single strain of bacteria (17). Furthermore, MAIT cells undergo MR1-dependent proliferation in vitro and in vivo in response to bacteria, for example, in the lungs of mice infected with Salmonella enterica serovar Typhimurium (32, 91, 161). The TCR repertoire of MAIT cells also supports microbemediated expansion. While the TCR repertoire is polyclonal in cord blood, it is oligoclonal in adult blood $(47,49,50,63)$, consistent with the hypothesized expansion of specific clones in response to particular bacteria. This is plausible, as MAIT cells with distinct TCRs are activated in vitro following stimulation with different bacteria (162), and in a human in vivo Salmonella enterica serovar Paratyphi A challenge setting, the relative abundance of different MAIT cell clonotypes changes in response to infection (163).

\section{Phenotypic and Functional Maturation}

In addition to expansion, MAIT cells undergo maturation in the periphery, as indicated by marked phenotypic changes. Approximately half of MAIT cells in the thymus are either DP or $\mathrm{CD}^{+}$, whereas MAIT cells in adult blood are predominantly $\mathrm{DN}$ or $\mathrm{CD}^{+}$(Figure 1D) $(16,49,102)$. Furthermore, CD8 ${ }^{+}$ MAIT cells in the thymus and cord blood are CD8 $\alpha \beta^{+}$, whereas roughly half of $\mathrm{CD} 8 \alpha^{+}$MAIT cells in adult blood express CD $8 \alpha \alpha$ homodimers $(16,63,102)$. CD8 $\alpha \alpha^{+}$MAIT cells are thought to arise from $C D 161{ }^{\text {hi }} C D 8 \alpha \beta^{+}$cells in the periphery $(47,63)$.
iNKT cells undergo similar phenotypic changes with age. $\mathrm{CD}^{+}$ cells comprise $80-90 \%$ of iNKT cells in human thymus and cord blood, and progressively decline in the periphery to comprise on average $40 \%$ of iNKT cells in adult blood $(15,73,158)$. This may result from the preferential peripheral expansion of $\mathrm{CD}^{-}$ iNKT cells, as CD4- ${ }^{-}$iNKT cells show reduced TREC content and increased proliferation in response to IL-15 compared with CD4 ${ }^{+}$iNKT cells (73). However, alternative explanations, such as CD4 downregulation, remain possible. It is unknown if $\mathrm{CD}^{+}$and $\mathrm{CD}^{+}$MAIT cells show differences in their proliferative capacity. Analogous to MAIT cells, a large proportion of $\mathrm{CD}^{+}$iNKT cells in human blood express CD8 $\alpha \alpha(61,62)$, but whether these arise in the periphery has not been investigated.

Following thymic exit, MAIT cells acquire a memory CD45RO ${ }^{+}$ phenotype and upregulate the expression of characteristic phenotypic markers, such as CD161 and IL-18R $\alpha$ (Figure 1D), while downregulating the expression of lymph node homing receptors, including CD62L and CCR7 (14, 47, 63, 102, 127, 155). These changes are gradual, as MAIT cells in cord blood, young blood, and adult blood exhibit an increasingly mature phenotype (47, 63, $102,127,155)$. iNKT cells undergo similar extrathymic phenotypic changes $(15,67,73,156,158,164)$, although they already exhibit a memory phenotype in the thymus and cord blood $(15,66,67,140)$. Upregulation of NK cell receptors on mouse iNKT cells is dependent on CD1d (142), while IL-7 can upregulate CD161 on human cord blood iNKT cells in vitro (74). The signals required for NK cell receptor upregulation on developing MAIT cells are currently unknown.

As well as phenotypic changes, MAIT cells undergo further functional differentiation following thymic exit. Although stage 3 MAIT cells in human thymus can produce IFN- $\gamma$ and TNF- $\alpha$ following PMA and ionomycin stimulation, their capacity to do so is significantly decreased compared with peripheral blood MAIT cells (102). Moreover, the majority of human MAIT cells may exit the thymus at stage 2 before they acquire effector capacity. In contrast to adult blood $\mathrm{V} \alpha 7.2^{+} \mathrm{CD} 161^{\text {hi }} \mathrm{T}$ cells, cord blood $\mathrm{V} \alpha 7.2^{+} \mathrm{CD} 161^{\text {hi }} \mathrm{T}$ cells are unable to produce IFN- $\gamma$ or Granzyme $\mathrm{B}$ in response to overnight stimulation with Escherichia coliinfected THP-1 cells (47). However, as MAIT cells comprise the majority of $\mathrm{V} \alpha 7.2^{+} \mathrm{CD} 161^{\text {hi }} \mathrm{T}$ cells in adult blood, but only a small fraction of $\mathrm{V} \alpha 7.2^{+} \mathrm{CD} 161^{\text {hi }} \mathrm{T}$ cells in cord blood (47), whether this finding also applies to MAIT cells needs to be confirmed using the MR1 tetramer. Similar to the findings for MAIT/V $\alpha 7.2^{+} \mathrm{CD} 161^{\mathrm{hi}}$ $\mathrm{T}$ cells, human thymic and cord blood iNKT cells appear functionally immature compared with adult blood iNKT cells. Early reports suggested that thymic and cord blood iNKT cells were incapable of cytokine production without prior in vitro expansion $(66,73)$. However, more recently, freshly isolated iNKT cells from the thymus and cord blood were shown to secrete cytokines, including IFN- $\gamma$, TNF- $\alpha$, and IL-4, in response to TCR and/ or PMA and ionomycin stimulation $(15,74)$. Consequently, the capacity of human thymic and cord blood iNKT cells to produce cytokines needs to be clarified. In contrast to human MAIT cells and iNKT cells, mouse thymic MAIT (102) and iNKT $(140,149,150)$ cells strongly produce cytokines, suggesting possible species-specific differences in when cytokine-producing capacity is acquired. 


\section{Homeostasis}

The requirements for MAIT cell proliferation and survival in the periphery are poorly understood (Figure 1E). Conventional memory T cells depend predominantly on cytokines for peripheral maintenance (165), suggesting stimulation with cytokines, as opposed to MR1, might be key for MAIT cell homeostasis. iNKT cells exhibit subset-specific requirements for cytokines. While IL-15 is indispensable for the survival and functional maturation of most iNKT cells in mice $(75,166)$, NKT17 cell homeostasis is exclusively dependent on IL-7 (76) (Figure 1E). Moreover, IL-15 and IL-7 preferentially stimulate the proliferation of $\mathrm{CD}^{-}$and $\mathrm{CD} 4^{+}$human iNKT cells, respectively (73). In contrast to iNKT cells, MAIT cells proliferate only in response to IL-15 (161), and not IL-7 (91), despite their exquisite sensitivity to stimulation with either cytokine (30,91, 167-169). Cytokines that signal via STAT3 are required for human MAIT and iNKT cell development and homeostasis, as indicated by the 4 - and 20 -fold reduction in their frequency, respectively, in patients with heterozygous loss-of-function mutations in STAT3 (77). The central role of STAT3 appears to be downstream of the IL-23 receptor (and possibly the IL-21 receptor) in MAIT cells, and the IL-21 receptor in iNKT cells. IL-18 is similarly necessary for MAIT cell development and/or survival, as IL-18-deficient mice exhibit reduced thymic and peripheral MAIT cell frequencies (102). Interestingly, the role of IL-18 appears independent of IL-18 receptor signaling, as MAIT cell development is normal in IL-18R $\alpha$-deficient mice (102). Therefore, further work is necessary to determine the specific role of IL-23 and IL-18 in regulating MAIT cell frequency and to establish the requirement for IL-7, IL-15, and additional cytokines in MAIT cell homeostasis. Furthermore, it remains to be investigated whether ROR $\gamma \mathrm{t}^{+}$MAIT cells and T-bet ${ }^{+}$ MAIT cells in mice are differentially regulated by cytokines, as has been demonstrated for the equivalent murine iNKT cell subsets.

It is unknown if tonic TCR signaling is necessary for MAIT cell homeostasis (Figure 1E). iNKT cell homeostasis in mice appears independent of CD1d (Figure 1E). iNKT cells can survive for weeks in the periphery of mice in the absence of CD1d $(142,170)$, and the homeostatic expansion of iNKT cells in lymphopenic hosts is CD1d independent $(75,166)$. By contrast, CD1d may play a role in human iNKT cell homeostasis through lipid antigen presentation on B cells. Compared with iNKT cells from total PBMCs, iNKT cells from B cell-depleted PBMCs (but not from PBMCs depleted of other $\mathrm{CD} 1 \mathrm{~d}^{+}$populations) display reduced proliferation and cytokine production in vitro upon stimulation with $\alpha$ GalCer + IL-2 (160). In addition, iNKT cells exhibit decreased frequency and altered functionality in systemic lupus erythematosus patients, associated with reduced CD1d expression on immature B cells $(160,171,172)$. Restoration of CD1d expression is sufficient to reverse these defects both in vitro and in vivo (160). Thus, it is worth examining whether MR1 has a role in MAIT cell homeostasis, particularly in humans. However, although MR1 is widely expressed by hematopoietic and nonhematopoietic cells, it is largely retained in the endoplasmic reticulum prior to ligand exposure (132, 173-175). Consequently, the ability of MR1 to modulate MAIT cell homeostasis may be limited compared with CD1d, which is frequently present at the cell surface (176).
In conclusion, MAIT cells and iNKT cells undergo further extrathymic maturation. However, while peripheral iNKT cell frequency remains relatively constant with age, MAIT cells undergo a large population expansion from birth to adulthood. B cells have an important, but differing, role in MAIT cell and iNKT cell peripheral development. Compared with MAIT cells, more is known about the role of cytokines in the peripheral maintenance of iNKT cells. Given that MAIT cells express similar cytokine receptors to iNKT cells, including the receptors for IL-7 and IL-15 (14), it is worth investigating the role of these cytokines in MAIT cell homeostasis and peripheral maturation. With the availability of MR1 tetramers $(12,13)$ and mice with an increased frequency of MAIT cells (35), this can now be examined in vivo using cytokine-deficient mice.

\section{Fetal Development}

Similar to human iNKT cells (64), human MAIT cells develop in fetal thymus and can be identified in both lymphoid and non-lymphoid peripheral tissues in the second trimester of fetal development (155). As the timing of early MAIT cell and iNKT cell development in humans is comparable $(47,64,155)$, and iNKT cells develop postnatally in mouse thymus $(150,177)$, it is likely that MAIT cells also undergo postnatal development in mice.

Before discussing human fetal MAIT cell development, it is important to note that, while fetal iNKT cell development has been studied using the CD1d tetramer, fetal MAIT cell development has so far only been investigated using the surrogate MAIT cell markers V $\alpha 7.2$ and CD161. As previously mentioned, the MAIT cell populations defined as MR1/5-OP-RU tetramer ${ }^{+}$ or $\mathrm{V} \alpha 7.2^{+} \mathrm{CD} 161^{\mathrm{hi}}$ are essentially the same in adult blood, while MR1/5-OP-RU tetramer ${ }^{+}$MAIT cells comprise $<20 \%$ of $\mathrm{V} \alpha 7.2^{+} \mathrm{CD} 161^{\text {hi }} \mathrm{T}$ cells at birth (47). Moreover, the majority of MAIT cells in human thymus are $\mathrm{CD} 161^{-} \mathrm{CD} 27^{+}$stage 2 cells, and stage 2 MAIT cells are also present at lower frequencies in cord blood and young blood ( $20 \%$ and $\sim 10 \%$ of MR1/5-OP-RU tetramer ${ }^{+}$MAIT cells, respectively) (102). Therefore, using V $\alpha 7.2$ and CD161 for fetal MAIT cell identification will fail to capture these CD161- MR1/5-OP-RU tetramer ${ }^{+}$MAIT cells. Overall, findings from the study of $\mathrm{V} \alpha 7.2^{+} \mathrm{CD} 161^{\text {hi }} \mathrm{T}$ cell development in fetal tissues may not accurately reflect the developmental pathway of MAIT cells. This should be taken into consideration when interpreting the findings discussed below, all of which were made using V $\alpha 7.2$ and CD161 to identify "MAIT" cells.

\section{Frequency and Localization}

During fetal development, $\mathrm{V} \alpha 7.2^{+} \mathrm{CD} 161^{\text {hi }} \mathrm{T}$ cells comprise $\sim 0.05 \%$ of $\mathrm{T}$ cells in human thymus, significantly lower than their frequency in adult blood (155). Their frequency in the thymus remains low and relatively constant after birth, at least up until the age of 14 (102). In contrast to MAIT cells, iNKT cell frequency in early fetal thymus is similar to that in adult blood $(\sim 0.1 \%$ of T cells) (156). However, their frequency decreases with gestational age in the thymus, cord blood, and neonatal peripheral blood, such that they are rare in postnatal thymus, while it increases in fetal peripheral tissues, particularly the small intestine and spleen $(47,64,73,156,158,178)$. This suggests a wave of iNKT cell 
development in the thymus early during fetal life (156), accompanied by the gradual population of peripheral tissues. This might also be true for MAIT cells, as the frequency of $\mathrm{V} \alpha 7.2^{+} \mathrm{CD} 161^{\mathrm{hi}}$ $\mathrm{T}$ cells in the blood of neonates decreases with gestational age (47). However, whether their thymic frequency also decreases, is currently unknown. Contrary to iNKT cells, no correlation was observed between gestational age and $\mathrm{V} \alpha 7.2^{+} \mathrm{CD} 161^{\text {hi }} \mathrm{T}$ cell frequency in fetal tissues (155), although the sample size was relatively low.

As in adults, $\mathrm{V} \alpha 7.2^{+} \mathrm{CD} 161^{\text {hi }} \mathrm{T}$ cells are enriched in fetal peripheral tissues, including the lung, liver, and small intestine, with lower frequencies in the thymus and secondary lymphoid organs (SLOs) (155). iNKT cells are similarly enriched in the small intestine, but relatively depleted in the liver, lung, and SLOs (64). The frequency of $\mathrm{V} \alpha 7.2^{+} \mathrm{CD} 161^{\text {hi }} \mathrm{T}$ cells in fetal tissues is low compared with the corresponding adult tissues, particularly in the liver, where they are $\sim 100$-fold less frequent in the fetus $(14,155)$. The frequency of human iNKT cells in adult peripheral tissues is poorly characterized, due to their low abundance. Nonetheless, at least in liver and spleen $(15,179,180)$, their frequency appears largely similar to that in fetal tissues.

\section{Phenotypic and Functional Maturation}

In all fetal tissues, $\mathrm{V} \alpha 7.2^{+} \mathrm{CD} 161^{\text {hi }} \mathrm{T}$ cells are less differentiated than in adult blood (155), analogous to iNKT cells $(64,74,156)$. Nevertheless, $\mathrm{V} \alpha 7.2^{+} \mathrm{CD} 161^{\text {hi }} \mathrm{T}$ cells in fetal peripheral tissues, particularly the small intestine, show a more mature phenotype than those in the thymus and SLOs, with increased expression of IL-18R $\alpha$ and CD45RO, and reduced expression of CD62L (155). In addition, peripheral tissue $\mathrm{V} \alpha 7.2^{+} \mathrm{CD} 161^{\text {hi }} \mathrm{T}$ cells are functionally more mature than their counterparts in lymphoid organs, producing increased IFN- $\gamma$ in vitro following $E$. coli stimulation (155). Similarly, iNKT cells are phenotypically and functionally more mature in peripheral tissues compared with lymphoid organs (64). However, while $\mathrm{V} \alpha 7.2^{+} \mathrm{CD} 161^{\text {hi }} \mathrm{T}$ cells are naïve in cord blood (16) and only a fraction express CD45RO in fetal thymus (155), $>80 \%$ of iNKT cells exhibit a memory CD45RO ${ }^{+}$ phenotype in both cord blood $(66,67)$ and fetal thymus $(156)$. Moreover, the proportion of $\mathrm{V} \alpha 7.2^{+} \mathrm{CD} 161^{\text {hi }} \mathrm{T}$ cells that produce IFN- $\gamma$ is significantly reduced in fetal peripheral tissues compared with adult blood (155), whereas iNKT cells in fetal small intestine and adult blood show largely comparable IFN- $\gamma$ production in response to $\alpha \mathrm{GalCer}$ (64). As iNKT cells from GF mice exhibit reduced cytokine production compared with their counterparts from standard SPF mice (181), and the fetal environment is typically thought to be sterile (182), it is perhaps surprising that fetal iNKT cells do not display reduced functionality compared with those in adult peripheral blood. However, this could be understood if the fetal environment was not entirely sterile, conflicting with the "sterile womb hypothesis" (182). In support of this suggestion, a number of recent papers provide evidence for the presence of microbes during fetal development, although these findings remain highly controversial [reviewed in Ref. (182)].

The discovery of mature $\mathrm{CD} 45 \mathrm{RO}^{+} \mathrm{V} \alpha 7.2^{+} \mathrm{CD} 161^{\text {hi }} \mathrm{T}$ cells in fetal peripheral tissues appears at odds with the requirement for commensal bacteria for the development and maturation of MAIT cells in mice $(17,22,102)$. Moreover, MAIT cells exhibit a naïve CD45RA+ phenotype in cord blood (16) and neonates (47), and rapidly upregulate $\mathrm{CD} 45 \mathrm{RO}$ following birth, concomitant with their exposure to riboflavin-synthesizing commensal bacteria $(14,16,47,102)$. This suggests microbe-driven maturation of human MAIT cells, akin to mouse MAIT cells. The reason for the discordant findings in fetal tissues and postnatal blood is currently unclear. As mentioned earlier, it is possible that MAIT cells in peripheral tissues comprise largely tissue-resident populations distinct from those in blood, similar to what has been proposed for iNKT cells based on parabiosis experiments in mice $(28,29)$. However, this has yet to be investigated for MAIT cells. Regardless, this would not explain why MAIT cells undergo maturation in fetal peripheral tissues. Maturation could be understood if the fetal environment was not completely GF, as discussed above. Alternatively, it is possible that other unknown factors can mediate fetal MAIT cell maturation.

In summary, we have a very limited understanding of fetal MAIT cell development. Only one paper has addressed MAIT cell development in human fetal tissues and the MR1 tetramer was not used in this study. Nevertheless, the findings for $\mathrm{V} \alpha 7.2^{+} \mathrm{CD} 161^{\text {hi }}$ $\mathrm{T}$ cells are reminiscent of iNKT cell fetal development, with $\mathrm{V} \alpha 7.2^{+} \mathrm{CD} 161^{\text {hi }} \mathrm{T}$ cells undergoing maturation in fetal peripheral tissues, particularly at mucosal sites. Now that MR1 tetramers are readily available, it will be necessary to establish whether MR1/5OP-RU tetramer ${ }^{+}$MAIT cells show similar fetal maturation to $\mathrm{V} \alpha 7.2^{+} \mathrm{CD} 161^{\text {hi }} \mathrm{T}$ cells and if so, to explore the factors driving such maturation.

\section{ACTIVATION}

\section{Mechanisms}

Analogous to iNKT cells, MAIT cells can be activated by TCR signals, cytokine signals independent of the TCR, or by combined TCR and cytokine signals (Figure 2).

The MAIT cell semi-invariant TCR recognizes bacterial and yeast riboflavin metabolite ligands in the context of MR1, with the most potent ligands being 5-OP-RU and 5-OE-RU [5-(2-oxoethylideneamino)-6-D-ribitylaminouracil] (Table 1; Figure 2A) (7, 13). By contrast, iNKT cells recognize various glycolipid and phospholipid antigens bound to CD1d (Table 1; Figure 2A), including glycosphingolipids from Sphingomonas spp. and Bacteroides fragilis, diacylglycerols from Borrelia burgdorferi and Streptococcus pneumoniae, and endogenous lysophospholipids (57). Although a wide range of lipid antigens have been identified for iNKT cells, compared with only a few for MAIT cells, the list of known antigens for both subsets is likely not exhaustive.

As the riboflavin synthesis pathway is present in diverse pathogenic and commensal bacteria, as well as in yeast, but absent in mammals, recognition of riboflavin metabolites enables MAIT cells to effectively discriminate self from non-self. No endogenous ligands have been identified for MAIT cells, although this is an active area of research. The ability of bacteria to activate MAIT cells in vitro strongly correlates with the presence of the riboflavin metabolic pathway (7) and activation of MAIT cells by a number of viruses, including dengue, influenza $\mathrm{A}$, and hepatitis C, is MR1-independent $(168,183-185)$. Thus, presentation of 


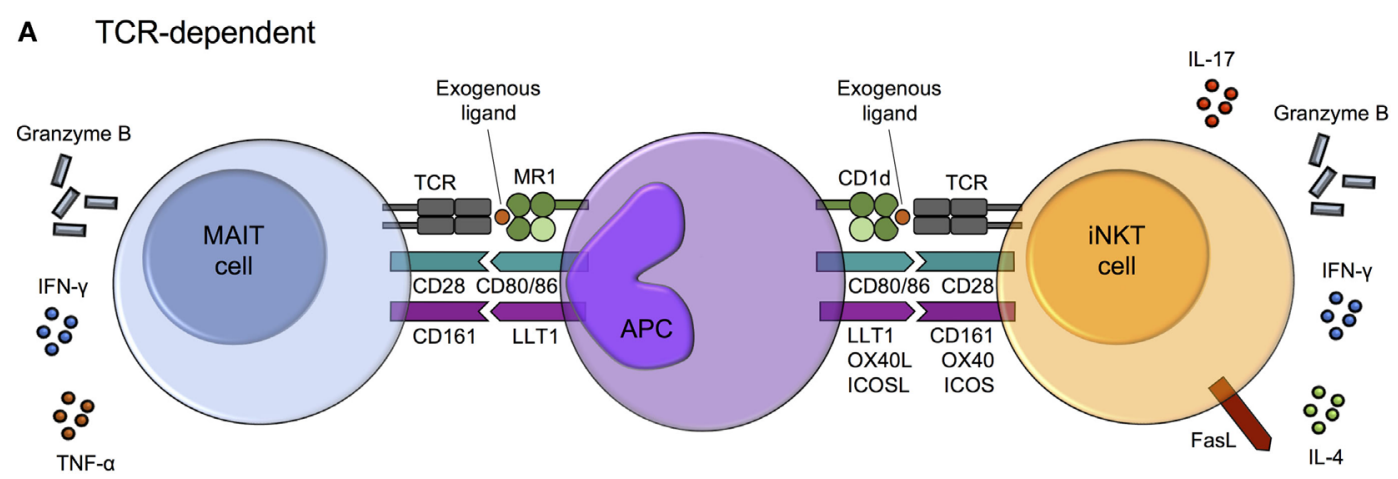

\section{B TCR-independent}

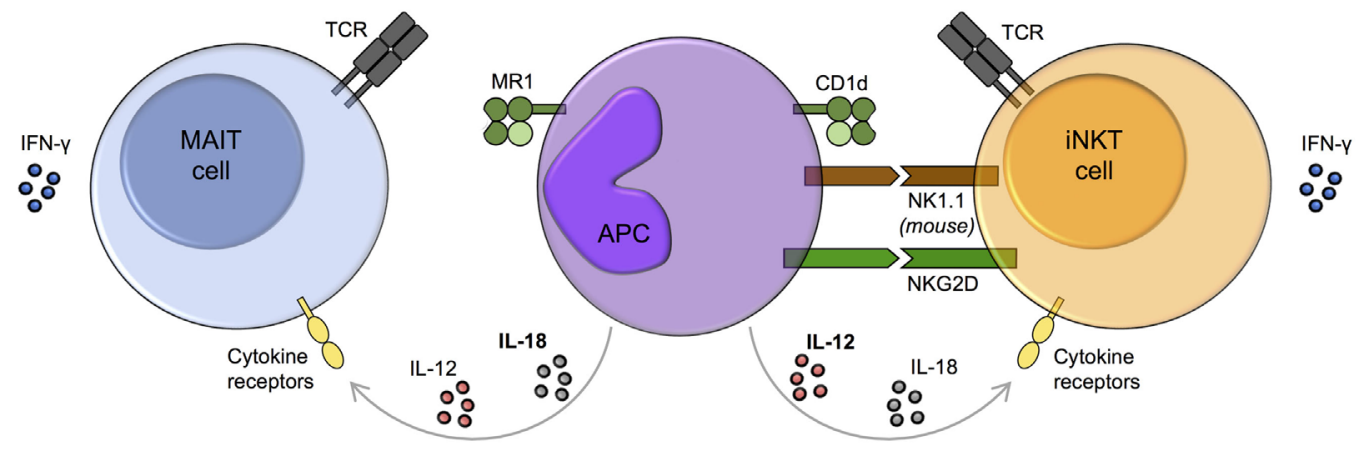

\section{TCR-dependent and -independent}

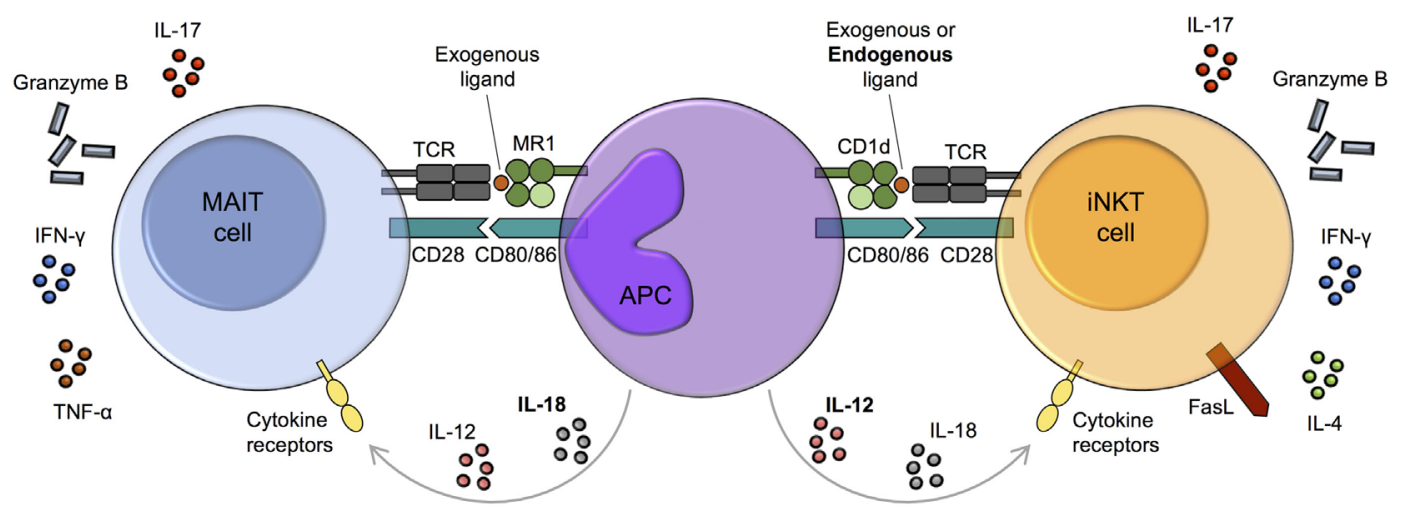

FIGURE 2 | Mechanisms of mucosal-associated invariant T (MAIT) cell and invariant natural killer T (iNKT) cell activation. MAIT cells and iNKT cells are activated via three main pathways: T cell receptor (TCR)-dependent (A), TCR-independent (predominantly cytokine-driven) (B), and combined TCR-dependent and -independent (C). (A) In response to TCR signaling, MAIT cells and iNKT cells produce cytokines and exhibit cytotoxic activity. The degree of activation is modulated by costimulatory molecules, including CD161. The array of cytokines produced by iNKT cells varies upon activation of different costimulatory pathways. Whether this is also the case for MAIT cells is currently unknown. (B) TCR-independent activation is largely cytokine-mediated, with similar combinations of cytokines capable of activating both MAIT cells and iNKT cells, for example, IL-12 + IL-18. However, while IL-12 (bold) appears dominant for iNKT cell activation, IL-18 (bold) is key for MAIT cells. Cytokine-dependent activation of MAIT and iNKT cells may require prior TCR stimulation, as has been reported for human iNKT cells. As well as by cytokines, iNKT cells can be directly activated via certain natural killer (NK) cell receptors, such as NK1.1 in mice. IFN- $\gamma$ production may predominate following TCR-independent activation, although this requires further investigation. (C) MAIT cells and iNKT cells can be activated through a combination of TCR and cytokine signaling. In this setting, iNKT cell antigens are typically weak self-antigens (bold), but endogenous ligands for MAIT cells have not been identified.

endogenous ligands by MR1 does not appear to be important for MAIT cell activation in bacterial or viral infections. However, endogenous ligands could have a key role in vivo in inflammation and cancer, or in specific infectious settings. This is plausible, as MR1 can bind endogenous ligands to activate non-MAIT T cells (119). In contrast with MAIT cells, self-lipid ligands are known 
to play a key role in iNKT cell biology. Although a number of endogenous ligands can activate iNKT cells, including lysophosphatidylcholine (human iNKT cells only) and ether-bonded mono-alkyl glycerophosphates $(186,187)$, recent evidence suggests that, at least in mice, $\alpha$-linked glycosylceramides are the major endogenous ligands (188).

In the absence of riboflavin metabolites, MAIT cells can be activated by cytokines independent of their TCR (Figure 2B). Similar to iNKT cells (189-192), they are potently activated by IL-12 + IL-18, as well as by various combinations of IL-12, IL-15, IL-18, and type I interferons (30, 167, 168, 193). In general, a single cytokine is insufficient to induce significant activation. MAIT cells express high levels of IL-18R $\alpha$ and IL-18 appears dominant for their TCR-independent activation, at least in viral infections (Figure 2B) $(17,168,183)$. By contrast, IL-12 is key for iNKT cell activation in the absence of TCR stimulation (Figure 2B) $(78,191,192)$.

It is unknown if MAIT cells are permanently amenable to TCR-independent cytokine stimulation. The capacity of human iNKT cells to respond to cytokine stimulation alone appears to reflect a transitory state that depends on prior TCR stimulation. In response to weak TCR stimulation by CD1d/ self-lipid, histone $\mathrm{H} 4$ acetylation at the IFNG locus leads to a transient increase in the responsiveness of iNKT cells to innate stimulation with IL-12 + IL-18 independent of additional TCR signaling, which decays over a period of hours to days (79). As iNKT cells adoptively transferred into $\mathrm{CD} \mathrm{d}^{-/-}$or $\mathrm{CD}^{\mathrm{d}} \mathrm{d}^{+/+}$mice show comparable responses to a number of bacteria and viruses (191, 194), cytokine-dependent activation of mouse iNKT cells may be entirely TCR independent. However, it remains possible that iNKT cells undergo TCR signaling in donor mice prior to adoptive transfer.

Mucosal-associated invariant $\mathrm{T}$ cells can integrate both TCR- and cytokine-dependent signals to augment functional capacity $(30,91,167,169,193,195,196)$, similar to iNKT cells (197-199) (Figure 2C). Many of the cytokines that can drive TCRindependent activation have been shown to costimulate TCR signaling for MAIT cells, including IL-12, IL-15, and/or IL-18. These are typically produced by antigen-presenting cells (APCs) downstream of TLR activation. MAIT cell activation following E. coli stimulation of THP-1 cells is mediated by TLR4-induced IL-12 + IL-18, combined with MR1-dependent TCR activation by microbial ligand(s) (193). In this model, early MAIT cell activation depends predominantly on TCR signals, while both TCR and cytokine signals are crucial at later time points. In a similar manner, iNKT cells are activated by self-lipids together with IL-12 following TLR4 or TLR7/8 stimulation of DCs (197, 198, 200). The mechanisms underlying TCR and cytokine synergy in MAIT cells and iNKT cells remain to be established. However, TCR signaling-induced histone acetylation at the IFNG locus (79), as discussed above, may play a role in iNKT cells.

As MAIT cells are hyporesponsive to stimulation via the TCR alone, synergy between TCR and cytokine signaling likely plays a key role in robust MAIT cell activation in vivo $(30,85,169)$. This is supported by a recent study showing that both metabolites from the riboflavin biosynthesis pathway and costimulatory signals are required for MAIT cell accumulation in vivo following bacterial lung infection (32). For iNKT cells, innate signaling from IL-12 provides the dominant signal for activation in many bacterial infections, even in the presence of cognate microbial lipid antigens (78). Cytokine signaling might also dominate in activating MAIT cells. TCR stimulation is insufficient to induce sustained MAIT cell effector responses in vitro (30), and in certain bacterial settings, blocking cytokines, as opposed to MR1, has a greater impact on MAIT cell activation $(195,201)$. Moreover, a central role for cytokines would potentially explain why MAIT cells are not constitutively activated by TCR-dependent sensing of commensal bacteria. However, the relative role of TCR- and cytokine-mediated activation will be influenced by many factors, including the nature of the APC. MAIT cell activation in response to Streptococcus pneumoniae in vitro is driven purely by cytokines when THP-1 cells are used as the APC, whereas in the presence of monocyte-derived macrophages, activation is driven by both MR1 and cytokines (201).

In addition to TCR- and cytokine-dependent activation, MAIT cells could potentially be activated via NK cell receptors, some of which can directly activate iNKT cells (Figure 2B). For example, NKG2D engagement triggers degranulation of human CD4- iNKT cells (202), and mouse iNKT cells produce IFN- $\gamma$ following crosslinking of NK1.1 (203), although the significance of TCR- and cytokine-independent activation in vivo remains unknown. In contrast to iNKT cells, direct NK cell receptor-mediated activation of MAIT cells has yet to be reported. Despite high expression of NKG2D (14), the cytotoxic activity of MAIT cells against $E$. coli-infected HeLa cells (overexpressing MR1) in vitro is unaffected by the presence of anti-NKG2D antibody (204). Nevertheless, reports have suggested both costimulatory and coinhibitory roles for the NK cell receptor CD161 on MAIT cells $(80,204)$. Similarly, CD161 can costimulate the activation of human iNKT cells (205).

\section{Regulation}

Costimulatory and coinhibitory molecules, including CD28, ICOS, OX40, and PD-1, have an important role in regulating iNKT cell activation and effector function in vitro and in vivo (Figure 2A) (206, 207). In addition to simply augmenting or dampening the magnitude of responses, engagement of specific costimulatory receptors on iNKT cells has been shown to skew the induced effector response $(206,207)$. For example, blocking the interaction of CD28 with CD86 more strongly inhibits IFN- $\gamma$ production compared with IL-4 production by murine iNKT cells in vitro in response to $\alpha \mathrm{GalCer}$, thus promoting a Th2-biased response (208). While MAIT cells express various costimulatory and coinhibitory molecules (209), we have limited understanding of their functional role, although a few have been shown to modulate MAIT cell effector function in vitro (85, 210-212). For example, costimulation with $\alpha \mathrm{CD} 28$ augments MAIT cell cytokine production and proliferation upon $\alpha \mathrm{CD} 3$ stimulation (85). By contrast, the coinhibitory molecule PD-1 is upregulated on MAIT cells in several bacterial and viral infections, including hepatitis C (213) and tuberculosis (TB) (211), and PD-1 blockade leads to enhanced IFN- $\gamma$ production by MAIT cells from active TB patients in response to in vitro stimulation with live bacillus Calmette-Guérin (211). Nevertheless, the role of costimulatory 
and coinhibitory molecules in modulating MAIT cell activation in vivo, and their capacity to differentially skew the MAIT cell effector response, has yet to be investigated.

In addition to the expression of coinhibitory molecules, two additional mechanisms may function to negatively regulate MAIT cell activation and/or to switch off MAIT cell effector functions upon resolution of infection or inflammation. First, MR1binding antagonist ligands, including 6-FP (6-formylpterin) and Ac-6-FP (acetyl-6-formylpterin), competitively inhibit MAIT cell activation in vitro in response to synthetic agonist ligand (Table 1) $(58,59,214)$. Furthermore, intranasal administration of Ac-6-FP can inhibit MAIT cell accumulation in a dose-dependent manner in the lungs of mice following intranasal administration of 5-OPRU and a TLR agonist (riboflavin-deficient Salmonella enterica serovar Typhimurium) (59). Second, MAIT cells exhibit a proapoptotic phenotype driven by PLZF, akin to iNKT cells (215). This sensitivity to activation-induced cell death may function to restrain the MAIT cell effector response in order to minimize immunopathology. However, the role of these mechanisms in regulating MAIT cell activation in physiological settings is currently unknown.

\section{Therapeutic Modulation}

Although microbe-driven TCR-dependent MAIT cell activation requires expression of the riboflavin biosynthesis pathway (7), non-riboflavin activating and inhibitory MR1 ligands have recently been identified (59). Keller et al. used various in silico approaches to screen libraries of small organic molecules and drugs for potential MR1 ligands (59). Identified targets were then tested for their ability to modulate MR1 expression and MAIT cell activation. Metabolites of the drug diclofenac were found to activate certain Jurkat MAIT cell lines in vitro, depending on their TCR $\beta$ chain usage, whereas 3-F-SA (3-formylsalicylic acid) could inhibit 5-OP-RU-dependent MAIT cell activation in vitro and in vivo (Table 1). While these findings imply that common therapeutics might inadvertently affect human MAIT cell activity in vivo, they also indicate the potential to design drugs to modulate MAIT cell function. Whether iNKT cell activation and function might also be influenced by common drugs is unknown. However, as lipid-based drug delivery systems are increasingly employed to improve oral bioavailability (216), it will be important to investigate the impact of such lipid-based formulations on iNKT cell function.

To summarize, diverse activation mechanisms are available for MAIT cells that are largely shared with iNKT cells. However, whereas iNKT cells can be activated by self-ligands in combination with cytokines, endogenous ligands for the MAIT cell TCR are yet to be identified. Due to their capacity for cytokine-mediated activation, MAIT cells and iNKT cells can play key roles in diverse infectious, as well as inflammatory and malignant diseases, even in the absence of their cognate microbial antigens. The relative importance of TCR- and cytokine-dependent activation in vivo is likely to be context-dependent and influenced by the nature of the pathogen and its TCR/TLR ligands, the type of activated APCs, the availability of costimulatory/coinhibitory molecules, and the stage of infection or inflammation. Nevertheless, the role for cytokines appears more important than for conventional $\mathrm{T}$ cell activation and may even dominate in MAIT cell and iNKT cell activation in some settings, despite the presence of microbial TCR ligands.

\section{EFFECTOR FUNCTIONS}

\section{Cytokine Production}

Upon activation, MAIT cells rapidly produce cytokines such as IFN- $\gamma$, TNF- $\alpha$, and IL-17 (Table 1) (14). MAIT cells typically secrete a limited range of pro-inflammatory cytokines. By contrast, iNKT cells secrete a huge variety of both pro- and antiinflammatory cytokines, including IL-4, IFN- $\gamma$, IL-10, and IL-17 (Table 1) (9).

The factors that govern which cytokines MAIT cells produce under different stimulatory conditions remain poorly characterized. Human MAIT cells secrete IFN- $\gamma$ following both TCR- and cytokine-dependent activation, whereas TNF- $\alpha$ production is more contingent on TCR signaling (Figure 2) $(14,30)$. Though all human MAIT cells express ROR $\gamma$ t, in addition to other type 17-associated molecules, such as CCR6 and the IL-23 receptor $(14,70)$, IL-17 production ex vivo is usually only detected following PMA and ionomycin stimulation $(14,70)$, and not upon TCR or cytokine stimulation alone $(14,30,85,169)$. However, certain cytokines, such as IL-7 or IL-23 + IL-1 $\beta$, can induce IL-17 production when combined with a TCR stimulus (169). In addition, MAIT cells may exhibit functional plasticity driven by cytokines, as has been demonstrated in vitro. For example, CD161 ${ }^{\text {hi }} \mathrm{CD} 8 \alpha^{+}$ $\mathrm{T}$ cells (predominantly MAIT cells) develop a more Tc1-like phenotype following culture with $\alpha \mathrm{CD} 3 / \alpha \mathrm{CD} 28+\mathrm{IL}-12$ for 14 days (85).

Similar to MAIT cells, the profile of cytokines produced by iNKT cells varies under different stimulation conditions and there is limited knowledge regarding the factors that regulate this. iNKT cells secrete both IFN- $\gamma$ and IL- 4 upon TCR stimulation with microbial antigens (Figure 2A) (217). By contrast, cytokine-dependent activation by viruses or TLR ligands stimulates predominantly IFN- $\gamma$ production and not IL-4 (Figure 2B) (217). Chemically modified analogs of the iNKT cell ligand $\alpha$ GalCer have been identified that induce qualitatively different cytokine responses in vitro and in vivo, specifically Th1-biased, Th2-biased, or mixed Th1/Th2 responses (218-220). Although the exact mechanisms for this remain unknown, the stability of ternary TCR-CD1d/glycolipid complexes appears to have an important role, with prolonged TCR stimulation favoring Th1biased responses $(218,220)$. As discussed, activation of different costimulatory pathways can also skew the iNKT cell response to antigen stimulation $(206,207)$. Therefore, the type of lipid antigens and costimulatory molecules available to activate iNKT cells in vivo will alter the nature of the cytokine response. Whether different MAIT cell ligands/chemical modifications of MAIT cell ligands, or costimulatory pathways, can skew MAIT cell cytokine production, remains to be investigated. As the range of cytokines produced by MAIT cells is less functionally diverse than that of iNKT cells, the capacity to drastically alter the overall immune response by skewing MAIT cell cytokine production may be more limited than with iNKT cells. 
Human MAIT cells in different tissues exhibit differential cytokine production. MAIT cells in the female genital mucosa appear skewed toward type 17 functions, secreting increased IL-17 and IL-22, and decreased IFN- $\gamma$ and TNF- $\alpha$, compared with blood MAIT cells (26). IL-22-secreting MAIT cells are also enriched in fetal small intestine (155), while MAIT cells in adipose tissue exhibit the unique capacity to secrete IL-10 (20). Different iNKT cell subsets preferentially localize to certain tissues in mice $(18,87)$. As a result, challenge with $\alpha$ GalCer induces distinct cytokine responses depending on the route of antigen delivery and thus the nature of the iNKT cell subsets activated (18). Whether variation in MAIT cell cytokine production across tissues can similarly be explained by the tissue-specific enrichment of different MAIT cell subsets is currently unknown. Of interest, IL-10-producing NKT10 cells preferentially localize to adipose tissue $(87,221)$, suggesting that the adipose tissueenriched IL-10-producing MAIT cells in humans could comprise a distinct subset (20).

\section{Cytotoxic Activity}

In addition to cytokine secretion, MAIT cells and iNKT cells display direct cytotoxic activity. MAIT cell killing is mediated via the Perforin/Granzyme pathway and is independent of Fas/FasL and NKG2D $(91,161,204)$. While their cytotoxic capacity (i.e., Perforin and Granzyme expression) is enhanced upon activation via the TCR and/or with cytokines, target cell killing is MR1 dependent (Figure 2) $(91,161,204)$. In contrast to MAIT cells, iNKT cell killing can be mediated via both Perforin/Granzymeand Fas/FasL-dependent pathways (Figure 2) $(62,98,222)$. The cytotoxic capacity of iNKT cells varies between subsets. Human CD4- iNKT cells show increased expression of cytotoxic molecules and superior cytotoxic activity compared with $\mathrm{CD} 4^{+}$cells $(62,223,224)$. Whether $\mathrm{CD}^{+}, \mathrm{CD}^{+}$, and DN MAIT cells show differences in cytotoxic activity is currently unknown. Akin to MAIT cells, iNKT cell cytotoxicity is largely dependent on CD1d and antigen, although alternative CD1d-independent mechanisms have been described $(202,222,224)$. In particular, human CD4- iNKT cells can kill targets through a CD1d-independent NKG2D-dependent pathway (202). MR1-independent pathways for MAIT cell killing have yet to be identified.

\section{Immune Interactions}

While knowledge of MAIT cell crosstalk with other immune cell subsets remains relatively limited, recent studies have identified important interactions with a number of immune cell types, including DCs, B cells, and NK cells. Through contact with myeloid cells, MAIT cells appear to have important immune regulatory functions. For example, upon antigen-specific activation, MAIT cells upregulate CD40L and induce CD40-dependent DC maturation, and in synergy with TLR ligands, promote the secretion of IL-12 (225). DC-derived IL-12 can subsequently enhance MAIT cell activation. MAIT cells can also influence monocyte differentiation in vivo. $\mathrm{MR}^{-1-}$ mice show enhanced susceptibility to pulmonary infection with Francisella tularensis live vaccine strain and delayed bacterial clearance (44). In this setting, MAIT cells promote early GM-CSF production in the lungs, resulting in the differentiation of inflammatory monocytes into DCs and the recruitment of activated $\mathrm{CD}^{+} \mathrm{T}$ cells into the lungs $(44,226)$. In addition to their effects on myeloid populations, MAIT cells can provide noncognate B cell help in vitro (227). In response to TCR-dependent or TCR- and cytokine-dependent activation, MAIT cells secrete factors that act on B cells to promote the differentiation of memory cells into plasmablasts and to increase antibody production (227). In these experiments, TCR stimulation was essential for the capacity of MAIT cells to provide B cell help (227). Finally, in the context of whole blood, activated MAIT cells promote NK cell transactivation in an MR1- and IL-18-dependent manner (225). Although MAIT cells can facilitate monocyte differentiation in vivo, whether the described crosstalk with DCs, B cells, and NK cells, occurs in vivo, and exactly where such interactions would take place, remains to be determined.

More is known about the immune interactions of iNKT cells. Through crosstalk with an array of immune cell types, iNKT cells can profoundly influence the nature and quality of both innate and adaptive immunity. iNKT cells engage in similar interactions to those described for MAIT cells; however, differences can be identified in the requirements for MAIT/iNKT cell activation in these settings and in the downstream effects on the immune response. Human iNKT cell clones drive monocyte differentiation in a CD1d-dependent manner (228). By contrast, MAIT cellmediated monocyte differentiation is MR1-independent, at least for transgenic MAIT cells in vitro (226). Analogous to MAIT cells, bidirectional interaction between iNKT cells and DCs leads to DC maturation and NK cell transactivation, but also results in increased peptide-specific $\mathrm{CD}^{+}$and $\mathrm{CD}^{+} \mathrm{T}$ cell responses $(229-$ 232). A similar function has yet to be described for MAIT cells. In addition to non-cognate $B$ cell help, iNKT cells can provide cognate B cell help (233). In some settings, help is provided by a dedicated subset of iNKT cells, known as follicular helper NKT $\left(\mathrm{NKT}_{\mathrm{FH}}\right)$ cells $(93,94,234)$. Other specialized iNKT cell subsets also engage in key immune interactions. For example, mouse and human Foxp $3^{+}$invariant regulatory NKT (iNKT reg $_{\text {) cells have }}$ been shown to suppress naïve $\mathrm{T}$ cell proliferation in vitro $(95,96)$. Whether comparable functions can be performed by specialized MAIT cell subsets is currently unknown.

In summary, iNKT cells and MAIT cells rapidly produce cytokines, exhibit cytotoxic activity, and can influence the function of both innate and adaptive immune cell populations. MAIT cells typically produce pro-inflammatory cytokines, whereas iNKT cells secrete vast amounts of both pro- and antiinflammatory cytokines. While immunoregulation via cytokine secretion is the dominant function of iNKT cells, the relative importance of cytokine secretion versus cytotoxic activity for MAIT cells, is currently unknown. iNKT cells profoundly influence the immune response through their crosstalk with other immune cell subsets, and limited studies reveal similar interactions for MAIT cells. Given their abundance in humans and their rapid effector function, MAIT cells are likely key orchestrators of innate and adaptive immunity in humans.

\section{SUBSETS}

Although human MAIT cells are thought to be largely homogeneous in phenotype and function, recent findings suggest that they 
may be more diverse than currently appreciated. Lepore et al. identified subpopulations of human MAIT cells with distinct cytokine secretion profiles (50), although whether these represent separate lineages is currently unknown. Human MAIT cells also show heterogeneous expression of certain NK cell-associated receptors, including CD56 and CD84, the expression of which correlates with their functional response to cytokine stimulation (209). Finally, MAIT cells in certain tissues exhibit altered cytokine production. For example, MAIT cells are skewed toward a Th17-like phenotype in female genital tract and express lower levels of the transcription factors PLZF and Eomes compared with peripheral blood MAIT cells (26), suggesting that they may comprise a distinct MAIT cell subset.

Mucosal-associated invariant T cells in humans can be $\mathrm{CD} 4^{+}$, $\mathrm{CD}^{+}$, or DN (Table 1) (16). Coreceptor expression appears to have little practical significance, particularly for $\mathrm{CD}^{+}$and $\mathrm{DN}$ MAIT cells $(43,235)$. However, limited studies have characterized the phenotype and function of the minor $\mathrm{CD} 4^{+}$population. Moreover, surrogate methods for MAIT cell identification were recently shown to poorly define $\mathrm{CD}^{+}$MAIT cells $(43,235)$, and thus findings from previous studies that used such approaches, require validation. Initial studies using the MR1/5-OP-RU tetramer indicate some disparity between $\mathrm{CD}^{+}$and $\mathrm{CD}^{+} / \mathrm{DN}$ subsets, including differential expression of certain transcription factors (PLZF, Eomes), chemokine receptors (CCR4, CXCR6), adhesion molecules (CD56), and NK cell receptors (NKG2A, NKG2D) $(43,235)$. Nevertheless, the role of the CD4 coreceptor and whether $\mathrm{CD}^{+}$MAIT cells comprise a distinct subset with specific functionality is currently unknown. Unlike MAIT cells, human $\mathrm{CD}^{+}, \mathrm{CD}^{+}$, and DN iNKT cells show clear phenotypic, functional, and transcriptional differences $(15,61,62,84,202$, 224, 236-240). However, given the considerable heterogeneity within each of these populations (15), it is unlikely that they represent genuine iNKT cell subsets.

The evidence for MAIT cell subsets in mice is more convincing. Two subsets of MAIT cells, a major ROR $\gamma \mathrm{t}^{+} \mathrm{IL}-17^{+}$population, and a smaller T-bet ${ }^{+}$IFN- $\gamma^{+}$subset have been identified in the thymus, spleen, and lung (Figure 3) $(19,102)$. These subsets can show plasticity in vivo. Following intranasal infection with Salmonella. enterica serovar Typhimurium, ROR $\gamma \mathrm{t}^{+}$MAIT cells in the lung upregulate T-bet expression to become ROR $\gamma \mathrm{t}^{+} \mathrm{T}$-bet ${ }^{+}$cells that can secrete either IL-17 or IFN- $\gamma$, though the majority produce IL-17 (32). In contrast to mice, human thymic and peripheral blood MAIT cells coexpress ROR $\gamma$ t and T-bet, although T-bet expression can similarly increase upon activation (85, 91, 102, 167). Furthermore, the majority of human MAIT cells express IFN- $\gamma$ and a smaller fraction produce IL-17, while some secrete both cytokines (Figure 3), highlighting important differences between mouse and human MAIT cells (14).

Similar to MAIT cells, iNKT cells in mice differentiate into distinct subsets within the thymus. These mirror conventional CD $4^{+}$ $\mathrm{T}$ helper cell subsets in their expression of master transcription factors and cytokines, namely PLZF ${ }^{\mathrm{lo}} \mathrm{T}-\mathrm{bet}^{+} \mathrm{ROR} \gamma \mathrm{t}^{-} \mathrm{NKT} 1$ cells that secrete IFN- $\gamma$, PLZF ${ }^{\text {hiT-bet }}{ }^{-}$ROR $\gamma t^{-}$NKT2 cells that secrete IL-4 and other Th2 cytokines, and PLZF ${ }^{\text {int }}$ T-bet ${ }^{-}$ROR $\gamma t^{+}$NKT17 cells that secrete IL-17A and IL-22 (Figure 3) (86, 241). NKT1, NKT2, and NKT17 cells show highly divergent transcriptional programs and differ in their expression of chemokine receptors, NK cell receptors, cytotoxic molecules, and cell cycle-related genes $(146,147,242)$. T-bet ${ }^{+}$IFN- $\gamma^{+}$and ROR $\gamma t^{+} I L-17^{+}$MAIT cells in mice could represent "MAIT1" and "MAIT17" subsets $(19,102)$, akin to NKT1 and NKT17 cells, respectively. By contrast, no "MAIT2" subset comparable to NKT2 cells has been identified, and MAIT cells in mice and humans show little to no production of Th2 cytokines $(14,19)$.

In addition to the major iNKT cell subsets that develop in the thymus, a number of minor, highly specialized subsets have been identified in mouse peripheral tissues and/or lymphoid organs, but not in the thymus. These include $\mathrm{NKT}_{\mathrm{FH}}$ cells $(93,234), \mathrm{iNKT}_{\text {reg }}$ cells (95), and IL-10-secreting NKT10 cells $(87,221)$. However, it is important to note that IL-10 can also be produced by activated NKT1, NKT2, and NKT17 cells following stimulation with $\alpha$ GalCer (243). Human iNKT cells with a similar phenotype and/ or function to $\mathrm{NKT}_{\mathrm{FH}}$ cells $(93)$, iNKT $\mathrm{Neg}_{\text {reg }}$ cells $(95,96)$, and NKT10 cells (87) have been reported (Figure 3). By contrast, comparable MAIT cell subsets have not been defined in mice or humans, although a high proportion of MAIT cells secrete IL-10 in human adipose tissue (Figure 3) (20). As NKT10 cells are enriched in mouse adipose tissue $(87,221)$, IL-10-secreting MAIT cells could represent a dedicated "MAIT10" subset. Whether MAIT cells can have regulatory or follicular helper-type functions is currently unknown.

In brief, two distinct MAIT cell subsets, analogous to NKT1 and NKT17 cells, are present in mice. Whereas the MAIT cell population is biased toward ROR $\gamma \mathrm{t} / \mathrm{IL}-17$ expression in C57BL/6 mice, iNKT cells favor the expression of T-bet/IFN- $\gamma$. This could suggest functional segregation between innate-like $\mathrm{T}$ cell populations in mice, although depending on the tissue and mouse strain, NKT17 cells might still be more abundant than MAIT cells. In comparison with mouse MAIT cells, human MAIT cells appear more homogeneous and exhibit a mixed Th1/Th17 phenotype, although there is evidence for some phenotypic and functional diversity. Moreover, human MAIT cells preferentially secrete IFN- $\gamma$ as opposed to IL-17. Multiple iNKT cell subsets are present in both mice and humans, although they are better defined in mice. Compared with MAIT cells, iNKT cells appear more functionally diverse, although it is possible that additional MAIT cell subsets remain to be identified.

\section{AVENUES FOR FUTURE MAIT CELL RESEARCH}

With the recent generation of MR1 tetramers $(12,13)$, it is now possible to detect MAIT cells in wild-type mice (19), as well as in human settings where MAIT cell frequency is low, for example in the thymus (102). Consequently, MAIT cells are now being studied in an increasingly wide variety of settings, including in numerous human diseases and animal disease models. Undoubtedly, this will lead to a greatly improved understanding of the role of MAIT cells in both health and disease.

Compared with iNKT cells, our knowledge of MAIT cell phenotype, development, regulation, and function remains limited and there are many important questions that need to be 


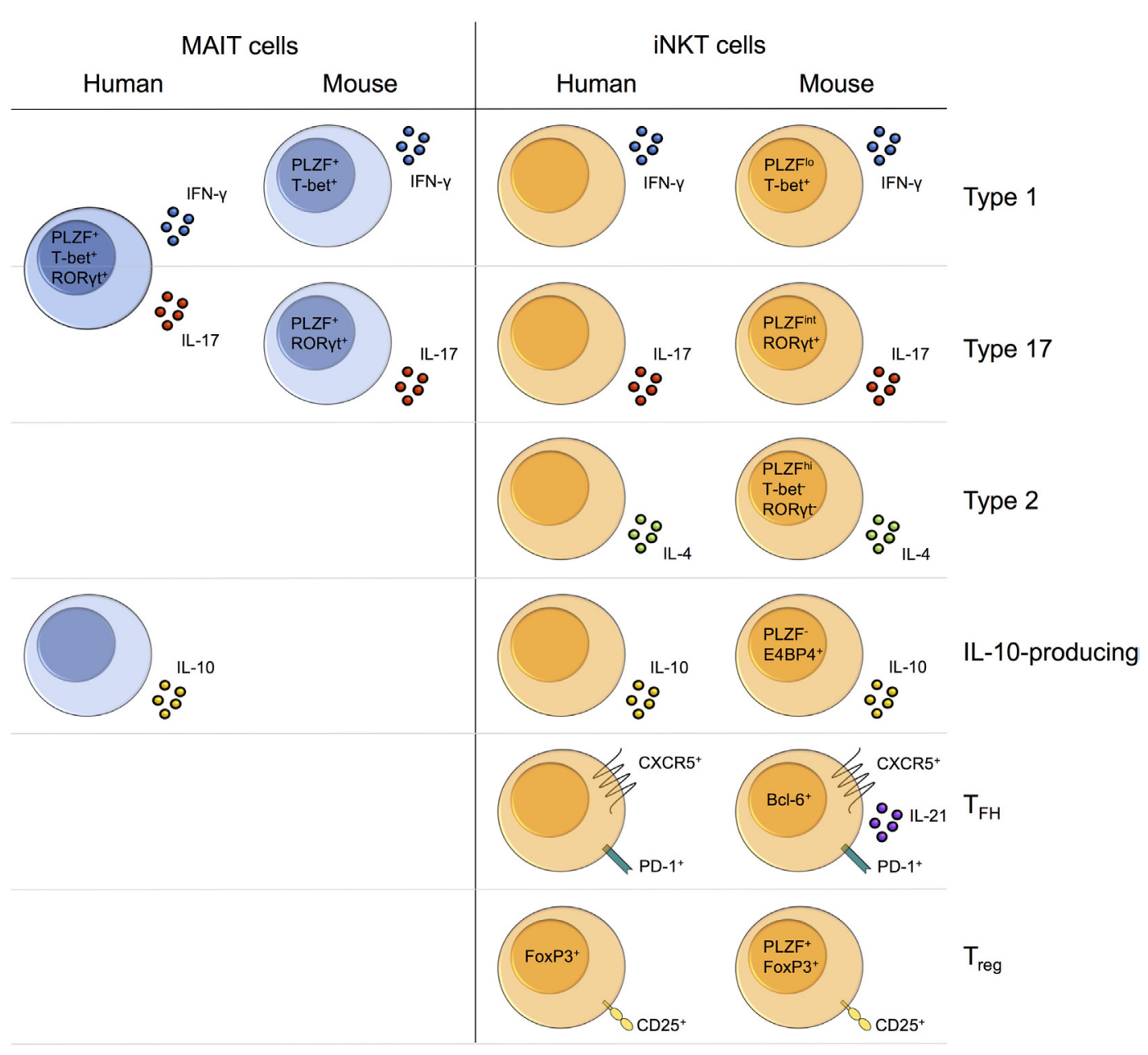

FIGURE 3 | Functional capacity of mucosal-associated invariant T (MAIT) cells and invariant natural killer T (iNKT) cells. Where subsets of MAIT or iNKT cells have been defined, characteristic cytokines, transcription factors, and/or surface markers, are illustrated. MAIT cells and iNKT cells exhibit overlapping functions, although a wider range of functions have been described for iNKT cells. In mice, distinct type 1 and type 17 MAIT and iNKT cell subsets have been identified. By contrast, human MAIT cells exhibit a mixed type 1/type 17 phenotype. Human iNKT cells secrete IFN- $\gamma$ and IL-17 (only in vitro under pro-inflammatory conditions), but whether these cytokines are produced by distinct subsets, remains to be established. Unlike MAIT cells, iNKT cells also show type 2 functions, such as IL-4 secretion. In mice, IL-10-producing iNKT cells comprise a distinct subset with altered transcription factor expression. Human MAIT cells and iNKT cells can produce IL-10, and human IL-10-producing MAIT cells are enriched in adipose tissue, similar to mouse NKT10 cells. However, whether these IL-10-producing populations comprise

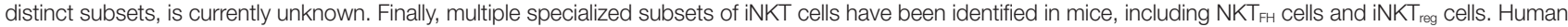
iNKT cells with similar phenotypes and/or functions have also been identified ( $N K T_{\text {reg }}$ only in vitro), but analogous populations have yet to be described for MAIT cells.

addressed. The search for novel MAIT cell ligands, both for their selection in the thymus, and their activation in the periphery, is a particularly active area of investigation. It is currently unknown whether MAIT cells can recognize endogenous antigens, analogous to iNKT cells, and if so, how these might influence MAIT cell development and function in vivo.

There are many gaps in our understanding of MAIT cell development, including the signals required for positive and potentially negative selection in the thymus; the transcriptional and epigenetic regulation of MAIT cell differentiation; and the timing and location of MAIT cell maturation. As MAIT cells appear to be mature in fetal tissues (155), but naïve in cord and neonatal blood $(16,47)$, they may comprise predominantly tissue-resident populations, similar to iNKT cells $(28,29,221)$. This could be addressed in parabiosis studies. Moreover, it will be important to determine the signals governing peripheral MAIT cell maturation and the maintenance of homeostasis. In addition to IL-18 and IL-23 $(77,102)$, it is worth investigating the role of IL-7 and IL-15, given MAIT cell responsiveness to these cytokines (30, 91, $167-169)$ and their function in iNKT cell homeostasis $(73,75$, $76,166,244)$. Whether MR1 is required for peripheral MAIT cell survival and maintenance in vivo is currently unknown, although CD1d does not appear to be essential for the homeostasis of iNKT cells $(75,142,166,170)$.

While MAIT cells can be activated through the TCR or with cytokines, or by a combination of both (11), which of these activation mechanisms predominates in vivo remains to be determined. iNKT cell activation appears to be dominantly 
driven by cytokines, even in settings where microbial ligands are present (78), although their sensitivity to cytokines alone may require prior TCR priming (79). It is hypothesized that cytokines might also be key for MAIT cell activation, especially given the indiscriminate expression of their ligands in both commensal and pathogenic bacteria $(7,17)$, and their relative hyporesponsiveness to TCR stimulation $(30,85,169)$. Despite expression of various NK cell receptors, costimulatory molecules, and immune checkpoint molecules $(14,209)$, how stimulation of these receptors modulates MAIT cell activation, is essentially unknown.

Similar to iNKT cells (86), transcriptionally and functionally distinct MAIT cell subsets have been identified in mice (19), although these require further characterization. Human MAIT cells exhibit a relatively uniform phenotype, and coexpress key transcription factors, suggesting a single MAIT cell subset $(14,91)$. However, recent studies indicate previously unappreciated phenotypic and functional heterogeneity in blood MAIT cells $(14,50,209)$, as well as skewed or unique functions in certain tissues $(20,26,155)$. Thus, the existence of specialized MAIT cell subsets remains an open question. In addition, it is unclear to what extent MAIT cells can show functional plasticity driven by environmental factors. It is likely that the presence of subsets and the ability of MAIT cells to display functional plasticity both contribute to MAIT cell diversity.

Recently, a number of studies have increased our knowledge of MAIT cell interactions with other immune cell populations (225-227), although our understanding of MAIT cell crosstalk remains much more limited than for iNKT cells (9). Furthermore, the role of MAIT cell interactions in vivo and their influence on the overall innate and adaptive immune response is largely unknown. As the interactions identified for MAIT cells resemble those of iNKT cells, it may be possible to use known iNKT cell interactions as a framework for the further investigation of MAIT cell crosstalk.

Though outside the scope of this review, we have little understanding of the role of MAIT cells in disease, despite their altered frequency and function in numerous infectious, inflammatory, and malignant diseases $(1,4,245)$. Given that MR1 tetramers are now widely available, it is possible to address the role of MAIT cells in vivo in models of disease. Recently, MR1 ligands have been discovered among drugs and drug-like molecules (59). This indicates the potential for the future development of therapeutics to modulate MAIT cell function (59), akin to the development of $\alpha \mathrm{GalCer}$ as a stand-alone therapy or vaccine adjuvant (246).

\section{CONCLUSION}

Invariant natural killer T cells have been more extensively studied than MAIT cells due to their higher frequency in mice, the earlier

\section{REFERENCES}

1. Rouxel O, Lehuen A. Mucosal-associated invariant T cells in autoimmune and immune-mediated diseases. Immunol Cell Biol (2018) 347:911. doi:10.1111/ imcb. 12011

2. Ussher JE, Willberg CB, Klenerman P. MAIT cells and viruses. Immunol Cell Biol (2018) 5:450. doi:10.1111/imcb.12008 development of tetramers for their specific identification, and the earlier generation of relevant transgenic mouse models. However, the MAIT cell field is growing rapidly, due to the recent development of the MR1 tetramer and hence the possibility to examine MAIT cells in wild-type mice. Comparison of MAIT cells to iNKT cells has in many cases identified shared biology. However, there are also instances in which comparison of MAIT cells to iNKT cells has revealed distinct biology. Therefore, while iNKT cell research provides a useful framework for the study of MAIT cells, it is important that both populations are studied individually, and findings from the iNKT cell field are not presumed to also apply to MAIT cells. Given their abundance in humans, their capacity for rapid cytokine production in response to TCR and/or cytokine stimulation, and their interactions with other immune cell populations, MAIT cells are likely key players in the immune system, both in health and disease. In support of this, they show altered phenotype and function in numerous human diseases, and exhibit protective or deleterious roles in mouse models of infection or inflammation. Consequently, MAIT cells represent an attractive target for therapeutic manipulation, especially considering their high frequency in humans and their recognition of a monomorphic $\mathrm{MHC}$-like molecule. To realize this goal, further research is necessary to develop a greater understanding of MAIT cell development, function, and regulation, and their specific roles in disease. We should continue to leverage our accumulated knowledge of iNKT cell biology as a platform to more completely understand the unique, and shared, biology of MAIT cells. In doing so, such investigations will likewise enhance our understanding of iNKT cell biology.

\section{AUTHOR CONTRIBUTIONS}

LG wrote the bulk of the manuscript and contributed to the figures. PK contributed to the planning, editing, and scope of the review. NP edited and revised the manuscript, and created the figures.

\section{ACKNOWLEDGMENTS}

We would like to thank Dr. Mariolina Salio and Dr. Chris Willberg for critical reading of the manuscript.

\section{FUNDING}

LG is supported by a Wellcome Trust $\mathrm{PhD}$ Studentship $[109028 / \mathrm{Z} / 15 / \mathrm{Z}]$. PK is funded by the Wellcome Trust [WT109965MA]; the Medical Research Council (STOP-HCV); and an NIHR Senior Fellowship; and the NIHR Biomedical Research Centre (Oxford). NP is supported by an Oxford-UCB Postdoctoral Fellowship.

3. Salou M, Franciszkiewicz K, Lantz O. MAIT cells in infectious diseases. Curr Opin Immunol (2017) 48:7-14. doi:10.1016/j.coi.2017. 07.009

4. Haeryfar SMM, Shaler CR, Rudak PT. Mucosa-associated invariant $\mathrm{T}$ cells in malignancies: a faithful friend or formidable foe? Cancer Immunol Immunother (2018) 178:1-12. doi:10.1007/s00262018-2132-1 
5. Hill TM, Bezbradica JS, Van Kaer L, Joyce S. CD1d-restricted natural killer T cells. In: eLS. Chichester: John Wiley \& Sons, Ltd (2016). doi:10.1002/9780470015902.a0020180.pub2

6. McEwen-Smith RM, Salio M, Cerundolo V. CD1d-dependent endogenous and exogenous lipid antigen presentation. Curr Opin Immunol (2015) 34: 116-25. doi:10.1016/j.coi.2015.03.004

7. Kjer-Nielsen L, Patel O, Corbett AJ, Le Nours J, Meehan B, Liu L, et al. MR1 presents microbial vitamin B metabolites to MAIT cells. Nature (2012) 491:717-23. doi:10.1038/nature11605

8. Franciszkiewicz K, Salou M, Legoux F, Zhou Q, Cui Y, Bessoles S, et al. MHC class I-related molecule, MR1, and mucosal-associated invariant T cells. Immunol Rev (2016) 272:120-38. doi:10.1111/imr.12423

9. Brennan PJ, Brigl M, Brenner MB. Invariant natural killer T cells: an innate activation scheme linked to diverse effector functions. Nat Rev Immunol (2013) 13:101-17. doi:10.1038/nri3369

10. Slauenwhite D, Johnston B. Regulation of NKT cell localization in homeostasis and infection. Front Immunol (2015) 6:255. doi:10.3389/ fimmu.2015.00255

11. Kurioka A, Walker LJ, Klenerman P, Willberg CB. MAIT cells: new guardians of the liver. Clin Transl Immunology (2016) 5:e98. doi:10.1038/cti.2016.51

12. Reantragoon R, Corbett AJ, Sakala IG, Gherardin NA, Furness JB, Chen Z, et al. Antigen-loaded MR1 tetramers define T cell receptor heterogeneity in mucosal-associated invariant T cells. J Exp Med (2013) 210:2305-20. doi:10.1084/jem.20130958

13. Corbett AJ, Eckle SBG, Birkinshaw RW, Liu L, Patel O, Mahony J, et al. T-cell activation by transitory neo-antigens derived from distinct microbial pathways. Nature (2014) 509:361-5. doi:10.1038/nature13160

14. Dusseaux M, Martin E, Serriari N, Péguillet I, Premel V, Louis D, et al. Human MAIT cells are xenobiotic-resistant, tissue-targeted, CD161hi IL-17-secreting T cells. Blood (2011) 117:1250-9. doi:10.1182/blood-2010-08-303339

15. Chan AC, Leeansyah e, Cochrane A, d' Udekem d' Acoz Y, Mittag D, Harrison LC, et al. Ex-vivo analysis of human natural killer T cells demonstrates heterogeneity between tissues and within established CD4+ and CD4- subsets. Clin Exp Immunol (2013) 172:129-37. doi:10.1111/cei.12045

16. Martin E, Treiner E, Duban L, Guerri L, Laude H, Toly C, et al. Stepwise development of MAIT cells in mouse and human. PLoS Biol (2009) 7:e54. doi:10.1371/journal.pbio.1000054

17. Le Bourhis L, Martin E, Péguillet I, Guihot A, Froux N, Coré M, et al. Antimicrobial activity of mucosal-associated invariant T cells. Nat Immunol (2010) 11:701-8. doi:10.1038/ni.1890

18. Lee YJ, Wang H, Starrett GJ, Phuong V, Jameson SC, Hogquist KA. Tissuespecific distribution of iNKT cells impacts their cytokine response. Immunity (2015) 43:566-78. doi:10.1016/j.immuni.2015.06.025

19. Rahimpour A, Koay HF, Enders A, Clanchy R, Eckle SBG, Meehan B, et al. Identification of phenotypically and functionally heterogeneous mouse mucosal-associated invariant T cells using MR1 tetramers. J Exp Med (2015) 212:1095-108. doi:10.1084/jem.20142110

20. Carolan E, Tobin LM, Mangan BA, Corrigan M, Gaoatswe G, Byrne G, et al. Altered distribution and increased IL-17 production by mucosalassociated invariant $\mathrm{T}$ cells in adult and childhood obesity. J Immunol (2015) 194:5775-80. doi:10.4049/jimmunol.1402945

21. Gold MC, Cerri S, Smyk-Pearson S, Cansler ME, Vogt TM, Delepine J, et al. Human mucosal associated invariant $\mathrm{T}$ cells detect bacterially infected cells. PLoS Biol (2010) 8:e1000407. doi:10.1371/journal.pbio.1000407

22. Treiner E, Duban L, Bahram S, Radosavljevic M, Wanner V, Tilloy F, et al. Selection of evolutionarily conserved mucosal-associated invariant $\mathrm{T}$ cells by MR1. Nature (2003) 422:164-9. doi:10.1038/nature01433

23. Fergusson JR, Huhn MH, Swadling L, Walker LJ, Kurioka A, Llibre A, et al. CD161intCD8+ T cells: a novel population of highly functional, memory CD8+ T cells enriched within the gut. Mucosal Immunol (2015) 9:401-13. doi:10.1038/mi.2015.69

24. Hiejima E, Kawai T, Nakase H, Tsuruyama T, Morimoto T, Yasumi T, et al. Reduced numbers and proapoptotic features of mucosal-associated invariant $\mathrm{T}$ cells as a characteristic finding in patients with inflammatory bowel disease. Inflamm Bowel Dis (2015) 21:1529-40. doi:10.1097/MIB.0000000000000397

25. Booth JS, Salerno-Goncalves R, Blanchard TG, Patil SA, Kader HA, Safta AM, et al. Mucosal-associated invariant $\mathrm{T}$ cells in the human gastric mucosa and blood: role in Helicobacter pylori infection. Front Immunol (2015) 6:466. doi:10.3389/fimmu.2015.00466
26. Gibbs A, Leeansyah E, Introini A, Paquin-Proulx D, Hasselrot K, Andersson E, et al. MAIT cells reside in the female genital mucosa and are biased towards IL-17 and IL-22 production in response to bacterial stimulation. Mucosal Immunol (2016) 10:35-45. doi:10.1038/mi.2016.30

27. Lynch L, O’Shea D, Winter DC, Geoghegan J, Doherty DG, O'Farrelly C. Invariant NKT cells and CDId+ cells amass in human omentum and are depleted in patients with cancer and obesity. Eur J Immunol (2009) 39: 1893-901. doi:10.1002/eji.200939349

28. Thomas SY, Scanlon ST, Griewank KG, Constantinides MG, Savage AK, Barr KA, et al. PLZF induces an intravascular surveillance program mediated by long-lived LFA-1-ICAM-1 interactions. J Exp Med (2011) 208:1179-88. doi:10.1084/jem.20102630

29. Scanlon ST, Thomas SY, Ferreira CM, Bai L, Krausz T, Savage PB, et al. Airborne lipid antigens mobilize resident intravascular NKT cells to induce allergic airway inflammation. J Exp Med (2011) 208:2113-24. doi:10.1084/ jem.20110522

30. Slichter CK, McDavid A, Miller HW, Finak G, Seymour BJ, McNevin JP, et al. Distinct activation thresholds of human conventional and innate-like memory T cells. JCI Insight (2016) 1:e86292. doi:10.1172/jci.insight.86292

31. Jeffery HC, van Wilgenburg B, Kurioka A, Parekh K, Stirling K, Roberts S, et al. Biliary epithelium and liver B cells exposed to bacteria activate intrahepatic MAIT cells through MR1. JExp Med (2016) 64(5):1118-27. doi:10.1016/j.jhep.2015.12.017

32. Chen Z, Wang H, D'Souza C, Sun S, Kostenko L, Eckle SBG, et al. Mucosalassociated invariant $\mathrm{T}$-cell activation and accumulation after in vivo infection depends on microbial riboflavin synthesis and co-stimulatory signals. Mucosal Immunol (2017) 10:58-68. doi:10.1038/mi.2016.39

33. Savage AK, Constantinides MG, Han J, Picard D, Martin E, Li B, et al. The transcription factor PLZF directs the effector program of the NKT cell lineage. Immunity (2008) 29:391-403. doi:10.1016/j.immuni.2008.07.011

34. Voillet V, Buggert M, Slichter CK, Berkson JD, Mair F, Addison MM, et al. Human MAIT cells exit peripheral tissues and recirculate via lymph in steady state conditions. JCI Insight (2018) 3:e98487. doi:10.1172/jci.insight.98487

35. Cui Y, Franciszkiewicz K, Mburu YK, Mondot S, Le Bourhis L, Premel V, et al. Mucosal-associated invariant $\mathrm{T}$ cell-rich congenic mouse strain allows functional evaluation. J Clin Invest (2015) 125:4171-85. doi:10.1172/JCI82424

36. Lee PT, Putnam A, Benlagha K, Teyton L, Gottlieb PA, Bendelac A. Testing the NKT cell hypothesis of human IDDM pathogenesis. J Clin Invest (2002) 110:793-800. doi:10.1172/JCI0215832

37. Matsuki N, Stanic AK, Embers ME, Van Kaer L, Morel L, Joyce S. Genetic dissection of V $\alpha 14 J \alpha 18$ natural $\mathrm{T}$ cell number and function in autoimmune-prone mice. J Immunol (2003) 170:5429-37. doi:10.4049/ jimmunol.170.11.5429

38. Esteban LM, Tsoutsman T, Jordan MA, Roach D, Poulton LD, Brooks A, et al. Genetic control of NKT cell numbers maps to major diabetes and lupus loci. J Immunol (2003) 171:2873-8. doi:10.4049/jimmunol.171.6.2873

39. Rymarchyk SL, Lowenstein H, Mayette J, Foster SR, Damby DE, Howe IW, et al. Widespread natural variation in murine natural killer T-cell number and function. Immunology (2008) 125:331-43. doi:10.1111/j.1365-2567.2008. 02846.x

40. Brodin P, Jojic V, Gao T, Bhattacharya S, Angel CJL, Furman D, et al. Variation in the human immune system is largely driven by non-heritable influences. Cell (2015) 160:37-47. doi:10.1016/j.cell.2014.12.020

41. Novak J, Dobrovolny J, Novakova L, Kozak T. The decrease in number and change in phenotype of mucosal-associated invariant $\mathrm{T}$ cells in the elderly and differences in men and women of reproductive age. Scand J Immunol (2014) 80:271-5. doi:10.1111/sji.12193

42. Walker LJ, Tharmalingam H, Klenerman P. The rise and fall of MAIT cells with age. Scand J Immunol (2014) 80:462-3. doi:10.1111/sji.12237

43. Gherardin NA, Souter MNT, Koay HF, Mangas KM, Seemann T, Stinear TP, et al. Human blood MAIT cell subsets defined using MR1 tetramers. Immunol Cell Biol (2018) 96(5):507-25. doi:10.1111/imcb.12021

44. Meierovics A, Yankelevich W-JC, Cowley SC. MAIT cells are critical for optimal mucosal immune responses during in vivo pulmonary bacterial infection. Proc Natl Acad Sci U S A (2013) 110:E3119-28. doi:10.1073/pnas. 1302799110

45. DelaRosa O, Tarazona R, Casado JG, Alonso C, Ostos B, Peña J, et al. V $\alpha 24+$ NKT cells are decreased in elderly humans. Exp Gerontol (2002) 37:213-7. doi:10.1016/S0531-5565(01)00186-3 
46. Crough T, Purdie DM, Okai M, Maksoud A, Nieda M, Nicol AJ. Modulation of human $\mathrm{V} \alpha 24(+) \mathrm{V} \beta 11(+)$ NKT cells by age, malignancy and conventional anticancer therapies. Br J Cancer (2004) 91:1880-6. doi:10.1038/sj. bjc. 6602218

47. Ben Youssef G, Tourret M, Salou M, Ghazarian L, Houdouin V, Mondot S, et al. Ontogeny of human mucosal-associated invariant $\mathrm{T}$ cells and related T cell subsets. J Exp Med (2018) 215(2):459-79. doi:10.1084/jem.20171739

48. Porcelli S, Yockey CE, Brenner MB, Balk SP. Analysis of T cell antigen receptor (TCR) expression by human peripheral blood CD4-8- $\alpha / \beta$ T cells demonstrates preferential use of several V $\beta$ genes and an invariant TCR $\alpha$ chain. J Exp Med (1993) 178:1-16. doi:10.1084/jem.178.1.1

49. Tilloy F, Treiner E, Park S-H, Garcia C, Lemonnier F, la Salle de H, et al. An invariant $\mathrm{T}$ cell receptor $\alpha$ chain defines a novel TAP-independent major histocompatibility complex class Ib-restricted $\alpha / \beta \mathrm{T}$ cell subpopulation in mammals. J Exp Med (1999) 189:1907-21. doi:10.1084/jem.189.12.1907

50. Lepore M, Kalinichenko A, Kalinicenko A, Colone A, Paleja B, Singhal A, et al. Parallel T-cell cloning and deep sequencing of human MAIT cells reveal stable oligoclonal TCR $\beta$ repertoire. Nat Commun (2014) 5:3866. doi:10.1038/ ncomms 4866

51. Dellabona P, Padovan E, Casorati G, Brockhaus M, Lanzavecchia A. An invariant $\mathrm{V} \alpha 4-\mathrm{J} \alpha \mathrm{Q} / \mathrm{V} \beta 11 \mathrm{~T}$ cell receptor is expressed in all individuals by clonally expanded CD4-8- T cells. J Exp Med (1994) 180:1171-6. doi:10.1084/jem. 180.3.1171

52. Lantz $\mathrm{O}$, Bendelac $\mathrm{A}$. An invariant $\mathrm{T}$ cell receptor $\alpha$ chain is used by a unique subset of major histocompatibility complex class I-specific CD4+ and CD48- T cells in mice and humans. J Exp Med (1994) 180:1097-106. doi:10.1084/ jem.180.3.1097

53. Matsuda JL, Gapin L, Fazilleau N, Warren K, Naidenko OV, Kronenberg M. Natural killer T cells reactive to a single glycolipid exhibit a highly diverse T cell receptor $\beta$ repertoire and small clone size. Proc Natl Acad Sci U S A (2001) 98:12636-41. doi:10.1073/pnas.221445298

54. Ronet C, Mempel M, Thieblemont N, Lehuen A, Kourilsky P, Gachelin G. Role of the complementarity-determining region 3 (CDR3) of the TCR- $\beta$ chains associated with the Vo14 semi-invariant TCR $\alpha$-chain in the selection of CD4+NK T cells. J Immunol (2001) 166:1755-62. doi:10.4049/jimmunol.166. 3.1755

55. Bendelac A, Lantz O, Quimby ME, Yewdell JW, Bennink JR, Brutkiewicz RR. CD1 recognition by mouse NK1+ T lymphocytes. Science (1995) 268:863-5. doi:10.1126/science.7538697

56. Exley M, Garcia J, Balk SP, Porcelli S. Requirements for CD1d recognition by human invariant V $\alpha 24+$ CD4-CD8- T cells. J Exp Med (1997) 186:109-20. doi:10.1084/jem.186.1.109

57. Kohlgruber AC, Donado CA, LaMarche NM, Brenner MB, Brennan PJ. Activation strategies for invariant natural killer T cells. Immunogenetics (2016) 68:649-63. doi:10.1007/s00251-016-0944-8

58. Eckle SBG, Birkinshaw RW, Kostenko L, Corbett AJ, McWilliam HEG, Reantragoon R, et al. A molecular basis underpinning the $\mathrm{T}$ cell receptor heterogeneity of mucosal-associated invariant T cells. J Exp Med (2014) 211:1585-600. doi:10.1084/jem.20140484

59. Keller AN, Eckle SBG, Xu W, Liu L, Hughes VA, Mak JYW, et al. Drugs and drug-like molecules can modulate the function of mucosal-associated invariant T cells. Nat Immunol (2017) 486:554. doi:10.1038/ni.3679

60. Matsuda JL, Naidenko OV, Gapin L, Nakayama T, Taniguchi M, Wang CR, et al. Tracking the response of natural killer $\mathrm{T}$ cells to a glycolipid antigen using CD1d tetramers. J Exp Med (2000) 192(5):741-54. doi:10.1084/jem. 192.5.741

61. Takahashi T, Chiba S, Nieda M, Azuma T, Ishihara S, Shibata Y, et al. Cutting edge: analysis of human Va24+CD8+ NK T cells activated by $\alpha$-galactosylceramide-pulsed monocyte-derived dendritic cells. JImmunol (2002) 168:3140-4. doi:10.4049/jimmunol.168.7.3140

62. Gumperz JE, Miyake S, Yamamura T, Brenner MB. Functionally distinct subsets of CD1d-restricted natural killer T cells revealed by CD1d tetramer staining. J Exp Med (2002) 195:625-36. doi:10.1084/jem.20011786

63. Walker LJ, Kang Y-H, Smith MO, Tharmalingham H, Ramamurthy N, Fleming VM, et al. Human MAIT and CD8 $\alpha \alpha$ cells develop from a pool of type-17 precommitted CD8+ T cells. Blood (2012) 119:422-33. doi:10.1182/ blood-2011-05-353789

64. Loh L, Ivarsson MA, Michaëlsson J, Sandberg JK, Nixon DF. Invariant natural killer $\mathrm{T}$ cells developing in the human fetus accumulate and mature in the small intestine. Mucosal Immunol (2014) 7:1233-43. doi:10.1038/mi. 2014.13

65. Kim CH, Johnston B, Butcher EC. Trafficking machinery of NKT cells: shared and differential chemokine receptor expression among V $\alpha 24(+) \mathrm{V} \beta 11(+)$ NKT cell subsets with distinct cytokine-producing capacity. Blood (2002) 100:11-6. doi:10.1182/blood-2001-12-0196

66. D’Andrea A, Goux D, de Lalla C, Koezuka Y, Montagna D, Moretta A, et al. Neonatal invariant V $\alpha 24+$ NKT lymphocytes are activated memory cells. Eur J Immunol (2000) 30:1544-50. doi:10.1002/1521-4141(200006) 30:6<1544::AID-IMMU1544>3.0.CO;2-I

67. van Der Vliet HJ, Nishi N, de Gruijl TD, Blomberg von BM, van den Eertwegh AJ, Pinedo HM, et al. Human natural killer T cells acquire a memory-activated phenotype before birth. Blood (2000) 95:2440-2. doi:10.1159/000416308

68. Prussin C, Foster B. TCR V alpha 24 and V beta 11 coexpression defines a human NK1 T cell analog containing a unique Th0 subpopulation. J Immunol (1997) 159:5862-70.

69. Hu T, Gimferrer I, Alberola Ila J. Control of early stages in invariant natural killer T-cell development. Immunology (2011) 134:1-7. doi:10.1111/ j.1365-2567.2011.03463.x

70. Billerbeck E, Kang Y-H, Walker L, Lockstone H, Grafmueller S, Fleming V, et al. Analysis of CD161 expression on human CD8+ T cells defines a distinct functional subset with tissue-homing properties. Proc Natl Acad Sci U S A (2010) 107:3006-11. doi:10.1073/pnas.0914839107

71. Johnston B, Kim CH, Soler D, Emoto M, Butcher EC. Differential chemokine responses and homing patterns of murine TCR $\alpha \beta$ NKT cell subsets. J Immunol (2003) 171:2960-9. doi:10.4049/jimmunol.171.6.2960

72. Rolf J, Berntman E, Stenström M, Smith EMK, Månsson R, Stenstad H, et al. Molecular profiling reveals distinct functional attributes of CD1drestricted natural killer (NK) T cell subsets. Mol Immunol (2008) 45:2607-20. doi:10.1016/j.molimm.2007.12.022

73. Baev DV, Peng X-H, Song L, Barnhart JR, Crooks GM, Weinberg KI, et al. Distinct homeostatic requirements of CD4+ and CD4- subsets of Vo24-invariant natural killer T cells in humans. Blood (2004) 104:4150-6. doi:10.1182/blood-2004-04-1629

74. De Lalla C, Festuccia N, Albrecht I, Chang H-D, Andolfi G, Benninghoff U, et al. Innate-like effector differentiation of human invariant NKT cells driven by IL-7. J Immunol (2008) 180:4415-24. doi:10.4049/jimmunol.180.7.4415

75. Ranson T, Vosshenrich CAJ, Corcuff E, Richard O, Laloux V, Lehuen A, et al. IL-15 availability conditions homeostasis of peripheral natural killer T cells. Proc Natl Acad Sci U S A (2003) 100:2663-8. doi:10.1073/ pnas. 0535482100

76. Webster KE, Kim H-O, Kyparissoudis K, Corpuz TM, Pinget GV, Uldrich AP, et al. IL-17-producing NKT cells depend exclusively on IL-7 for homeostasis and survival. Mucosal Immunol (2014) 7:1058-67. doi:10.1038/mi. 2013.122

77. Wilson RP, Ives ML, Rao G, Lau A, Payne K, Kobayashi M, et al. STAT3 is a critical cell-intrinsic regulator of human unconventional $\mathrm{T}$ cell numbers and function. J Exp Med (2015) 212:855-64. doi:10.1084/jem.20141992

78. Brigl M, Tatituri RVV, Watts GFM, Bhowruth V, Leadbetter EA, Barton N, et al. Innate and cytokine-driven signals, rather than microbial antigens, dominate in natural killer $\mathrm{T}$ cell activation during microbial infection. J Exp Med (2011) 208:1163-77. doi:10.1084/jem.20102555

79. Wang X, Bishop KA, Hegde S, Rodenkirch LA, Pike JW, Gumperz JE. Human invariant natural killer $\mathrm{T}$ cells acquire transient innate responsiveness via histone H4 acetylation induced by weak TCR stimulation. J Exp Med (2012) 209:987-1000. doi:10.1084/jem.20111024

80. Fergusson JR, Smith KE, Fleming VM, Rajoriya N, Newell EW, Simmons R, et al. CD161 defines a transcriptional and functional phenotype across distinct human T cell lineages. Cell Rep (2014) 9:1075-88. doi:10.1016/j. celrep.2014.09.045

81. Gleimer M, Boehmer von H, Kreslavsky T. PLZF controls the expression of a limited number of genes essential for NKT cell function. Front Immunol (2012) 3:374. doi:10.3389/fimmu.2012.00374

82. Coquet JM, Chakravarti S, Kyparissoudis K, McNab FW, Pitt LA, McKenzie BS, et al. Diverse cytokine production by NKT cell subsets and identification of an IL-17-producing CD4-NK1.1- NKT cell population. Proc Natl Acad Sci U S A (2008) 105:11287-92. doi:10.1073/pnas.0801631105

83. Rachitskaya AV, Hansen AM, Horai R, Li Z, Villasmil R, Luger D, et al. Cutting edge: NKT cells constitutively express IL-23 receptor and ROR $\gamma \mathrm{t}$ 
and rapidly produce IL-17 upon receptor ligation in an IL-6-independent fashion. J Immunol (2008) 180:5167-71. doi:10.4049/jimmunol.180.8.5167

84. Lee PT, Benlagha K, Teyton L, Bendelac A. Distinct functional lineages of human V $\alpha 24$ natural killer T cells. J Exp Med (2002) 195:637-41. doi:10.1084/ jem.20011908

85. Turtle CJ, Delrow J, Joslyn RC, Swanson HM, Basom R, Tabellini L, et al. Innate signals overcome acquired TCR signaling pathway regulation and govern the fate of human CD161(hi) CD8 $\alpha+$ semi-invariant T cells. Blood (2011) 118:2752-62. doi:10.1182/blood-2011-02-334698

86. Lee YJ, Holzapfel KL, Zhu J, Jameson SC, Hogquist KA. Steady-state production of IL-4 modulates immunity in mouse strains and is determined by lineage diversity of iNKT cells. Nat Immunol (2013) 14:1146-54. doi:10.1038/ ni. 2731

87. Sag D, Krause P, Hedrick CC, Kronenberg M, Wingender G. IL-10-producing NKT10 cells are a distinct regulatory invariant NKT cell subset. J Clin Invest (2014) 124:3725-40. doi:10.1172/JCI72308

88. Snyder-Cappione JE, Tincati C, Eccles-James IG, Cappione AJ, Ndhlovu LC, Koth LL, et al. A comprehensive ex vivo functional analysis of human NKT cells reveals production of MIP1- $\alpha$ and MIP1- $\beta$, a lack of IL-17, and a Th1-bias in males. PLoS One (2010) 5:e15412. doi:10.1371/journal.pone. 0015412

89. Havenith SHC, Yong SL, Henson SM, Piet B, Idu MM, Koch SD, et al. Analysis of stem-cell-like properties of human CD161++IL-18R $\alpha+$ memory CD8+ T cells. Int Immunol (2012) 24:625-36. doi:10.1093/intimm/dxs069

90. Gao Y, Rae W, Ramakrishnan KA, Barcenas-Morales G, Döffinger R, Eren E, et al. Mucosal-associated invariant T (MAIT) cells are impaired in Th17 associated primary and secondary immunodeficiencies. PLoS One (2016) 11:e0155059. doi:10.1371/journal.pone.0155059

91. Leeansyah E, Svärd J, Dias J, Buggert M, Nyström J, Quigley MF, et al. Arming of MAIT cell cytolytic antimicrobial activity is induced by IL-7 and defective in HIV-1 infection. PLoS Pathog (2015) 11:e1005072. doi:10.1371/journal. ppat. 1005072

92. Kovalovsky D, Uche OU, Eladad S, Hobbs RM, Yi W, Alonzo E, et al. The BTB-zinc finger transcriptional regulator PLZF controls the development of invariant natural killer T cell effector functions. Nat Immunol (2008) 9:1055-64. doi:10.1038/ni.1641

93. Chang P-P, Barral P, Fitch J, Pratama A, Ma CS, Kallies A, et al. Identification of Bcl-6-dependent follicular helper NKT cells that provide cognate help for B cell responses. Nat Immunol (2012) 13:35-43. doi:10.1038/ni.2166

94. Tonti E, Fedeli M, Napolitano A, Iannacone M, Andrian von UH, Guidotti LG, et al. Follicular helper NKT cells induce limited B cell responses and germinal center formation in the absence of CD4(+) T cell help. JImmunol (2012) 188:3217-22. doi:10.4049/jimmunol.1103501

95. Monteiro M, Almeida CF, Caridade M, Ribot JC, Duarte J, Agua-Doce A, et al. Identification of regulatory Foxp3+ invariant NKT cells induced by TGF- $\beta$. J Immunol (2010) 185:2157-63. doi:10.4049/jimmunol.1000359

96. Moreira-Teixeira L, Resende M, Devergne O, Herbeuval J-P, Hermine O, Schneider E, et al. Rapamycin combined with TGF- $\beta$ converts human invariant NKT cells into suppressive Foxp3+ regulatory cells. J Immunol (2012) 188:624-31. doi:10.4049/jimmunol.1102281

97. Knox JJ, Cosma GL, Betts MR, McLane LM. Characterization of T-Bet and Eomes in peripheral human immune cells. Front Immunol (2014) 5:217. doi:10.3389/fimmu.2014.00217

98. Takahashi T, Nieda M, Koezuka Y, Nicol A, Porcelli SA, Ishikawa Y, et al. Analysis of human V $\alpha 24+\mathrm{CD} 4+$ NKT cells activated by $\alpha$-glycosylceramide-pulsed monocyte-deriveddendriticcells.J Immunol(2000) 164:4458-64.doi:10.4049/ jimmunol.164.9.4458

99. Benlagha K, Weiss A, Beavis A, Teyton L, Bendelac A. In vivo identification of glycolipid antigen-specific T cells using fluorescent CD1d tetramers. J Exp Med (2000) 191:1895-903. doi:10.1084/jem.191.11.1895

100. Cheroutre H, Lambolez F. Doubting the TCR coreceptor function of CD8 $\alpha \alpha$. Immunity (2008) 28:149-59. doi:10.1016/j.immuni.2008.01.005

101. Sandberg JK, Bhardwaj N, Nixon DF. Dominant effector memory characteristics, capacity for dynamic adaptive expansion, and sex bias in the innate $V \alpha 24$ NKT cell compartment. Eur J Immunol (2003) 33:588-96. doi:10.1002/eji. 200323707

102. Koay HF, Gherardin NA, Enders A, Loh L, Mackay LK, Almeida CF, et al. A three-stage intrathymic development pathway for the mucosal-associated invariant T cell lineage. Nat Immunol (2016) 17:1300-11. doi:10.1038/ni.3565
103. Kawachi I, Maldonado J, Strader C, Gilfillan S. MR1-restricted Vo19i mucosal-associated invariant $\mathrm{T}$ cells are innate $\mathrm{T}$ cells in the gut lamina propria that provide a rapid and diverse cytokine response. J Immunol (2006) 176: 1618-27. doi:10.4049/jimmunol.176.3.1618

104. Croxford JL, Miyake S, Huang Y-Y, Shimamura M, Yamamura T. Invariant V $\alpha 19$ i T cells regulate autoimmune inflammation. Nat Immunol (2006) 7:987-94. doi:10.1038/ni1370

105. Bendelac A, Hunziker RD, Lantz O. Increased interleukin 4 and immunoglobulin E production in transgenic mice overexpressing NK1 T cells. J Exp Med (1996) 184:1285-93. doi:10.1084/jem.184.4.1285

106. Taniguchi M, Koseki H, Tokuhisa T, Masuda K, Sato H, Kondo E, et al. Essential requirement of an invariant $\mathrm{V} \alpha 14 \mathrm{~T}$ cell antigen receptor expression in the development of natural killer T cells. Proc Natl Acad Sci U S A (1996) 93:11025-8. doi:10.1073/pnas.93.20.11025

107. Wakao H, Kawamoto H, Sakata S, Inoue K, Ogura A, Wakao R, et al. A novel mouse model for invariant NKT cell study. J Immunol (2007) 179:3888-95. doi:10.4049/jimmunol.179.6.3888

108. Ren Y, Dashtsoodol N, Watarai H, Koseki H, Quan C, Taniguchi M. Generation of induced pluripotent stem cell-derived mice by reprogramming of a mature NKT cell. Int Immunol (2014) 26:551-61. doi:10.1093/intimm/dxu057

109. Kawano T. CD1d-restricted and TCR-mediated activation of V $\alpha 14$ NKT cells by glycosylceramides. Science (1997) 278:1626-9. doi:10.1126/science. 278.5343.1626

110. Cui J, Shin T, Kawano T, Sato H, Kondo E, Toura I, et al. Requirement for Vo14 NKT cells in IL-12-mediated rejection of tumors. Science (1997) 278:1623-6. doi:10.1126/science.278.5343.1623

111. Bedel R, Matsuda JL, Brigl M, White J, Kappler J, Marrack P, et al. Lower TCR repertoire diversity in Traj18-deficient mice. Nat Immunol (2012) 13:705-6. doi:10.1038/ni.2347

112. Chandra S, Zhao M, Budelsky A, de Mingo Pulido A, Day J, Fu Z, et al. A new mouse strain for the analysis of invariant NKT cell function. Nat Immunol (2015) 16:799-800. doi:10.1038/ni.3203

113. Dashtsoodol N, Shigeura T, Ozawa R, Harada M, Kojo S, Watanabe T, et al. Generation of novel Traj18-deficient mice lacking V $\alpha 14$ natural killer T cells with an undisturbed T cell receptor $\alpha$-chain repertoire. PLoS One (2016) 11:e0153347. doi:10.1371/journal.pone.0153347

114. Zhang J, Bedel R, Krovi SH, Tuttle KD, Zhang B, Gross J, et al. Mutation of the Traj18 gene segment using TALENs to generate natural killer T cell deficient mice. Sci Rep (2016) 6:27375. doi:10.1038/srep27375

115. Ren Y, Sekine-Kondo E, Shibata R, Kato-Itoh M, Umino A, Yanagida A, et al. A novel mouse model of iNKT cell-deficiency generated by CRISPR/Cas9 reveals a pathogenic role of iNKT cells in metabolic disease. Sci Rep (2017) 7:483. doi:10.1038/s41598-017-12475-4

116. Chen YH, Chiu NM, Mandal M, Wang N, Wang CR. Impaired NK1+ T cell development and early IL-4 production in CD1-deficient mice. Immunity (1997) 6:459-67. doi:10.1016/S1074-7613(00)80289-7

117. Mendiratta SK, Martin WD, Hong S, Boesteanu A, Joyce S, Van Kaer L. $\mathrm{CD} 1 \mathrm{~d} 1$ mutant mice are deficient in natural $\mathrm{T}$ cells that promptly produce IL-4. Immunity (1997) 6:469-77. doi:10.1016/S1074-7613(00)80290-3

118. Smiley ST, Kaplan MH, Grusby MJ. Immunoglobulin E production in the absence of interleukin-4-secreting CD1-dependent cells. Science (1997) 275:977-9. doi:10.1126/science.275.5302.977

119. Lepore M, Kalinichenko A, Calogero S, Kumar P, Paleja B, Schmaler M, et al. Functionally diverse human $\mathrm{T}$ cells recognize non-microbial antigens presented by MR1. Elife (2017) 6:e24476. doi:10.7554/eLife.24476

120. Greenaway HY, Ng B, Price DA, Douek DC, Davenport MP, Venturi V. NKT and MAIT invariant TCR $\alpha$ sequences can be produced efficiently by VJ gene recombination. Immunobiology (2013) 218:213-24. doi:10.1016/j. imbio.2012.04.003

121. Huang C, Kanagawa O. Ordered and coordinated rearrangement of the TCR $\alpha$ locus: role of secondary rearrangement in thymic selection. J Immunol (2001) 166:2597-601. doi:10.4049/jimmunol.166.4.2597

122. Guo J, Hawwari A, Li H, Sun Z, Mahanta SK, Littman DR, et al. Regulation of the TCR $\alpha$ repertoire by the survival window of $\mathrm{CD} 4(+) \mathrm{CD} 8(+)$ thymocytes. Nat Immunol (2002) 3:469-76. doi:10.1038/ni791

123. Egawa T, Eberl G, Taniuchi I, Benlagha K, Geissmann F, Hennighausen L, et al. Genetic evidence supporting selection of the Vo14i NKT cell lineage from double-positive thymocyte precursors. Immunity (2005) 22:705-16. doi:10.1016/j.immuni.2005.03.011 
124. Bezbradica JS, Hill T, Stanic AK, Van Kaer L, Joyce S. Commitment toward the natural $\mathrm{T}$ (iNKT) cell lineage occurs at the CD4+8+ stage of thymic ontogeny. Proc Natl Acad Sci U S A (2005) 102:5114-9. doi:10.1073/ pnas.0408449102

125. Okada S, Markle JG, Deenick EK, Mele F, Averbuch D, Lagos M, et al. Impairment of immunity to Candida and Mycobacterium in humans with bi-allelic RORC mutations. Science (2015) 349:606-13. doi:10.1126/science. aaa 4282

126. Seach N, Guerri L, Le Bourhis L, Mburu Y, Cui Y, Bessoles S, et al. Double positive thymocytes select mucosal-associated invariant T cells. J Immunol (2013) 191:6002-9. doi:10.4049/jimmunol.1301212

127. Gold MC, Eid T, Smyk-Pearson S, Eberling Y, Swarbrick GM, Langley SM, et al. Human thymic MR1-restricted MAIT cells are innate pathogen-reactive effectors that adapt following thymic egress. Mucosal Immunol (2013) 6:35-44. doi:10.1038/mi.2012.45

128. Bendelac A. Positive selection of mouse NK1+ T cells by CD1-expressing cortical thymocytes. J Exp Med (1995) 182:2091-6. doi:10.1084/jem.182.6.2091

129. Coles MC, Raulet DH. NK1.1+ T cells in the liver arise in the thymus and are selected by interactions with class I molecules on CD4+CD8+ cells. J Immunol (2000) 164:2412-8. doi:10.4049/jimmunol.164.5.2412

130. Bendelac A, Savage PB, Teyton L. The biology of NKT cells. Annu Rev Immunol (2007) 25:297-336. doi:10.1146/annurev.immunol.25.022106.141711

131. Huang S, Gilfillan S, Cella M, Miley MJ, Lantz O, Lybarger L, et al. Evidence for MR1 antigen presentation to mucosal-associated invariant T cells. J Biol Chem (2005) 280:21183-93. doi:10.1074/jbc.M501087200

132. Huang S, Gilfillan S, Kim S, Thompson B, Wang X, Sant AJ, et al. MR1 uses an endocytic pathway to activate mucosal-associated invariant T cells. J Exp Med (2008) 205:1201-11. doi:10.1084/jem.20072579

133. Stritesky GL, Jameson SC, Hogquist KA. Selection of self-reactive T cells in the thymus. Annu Rev Immunol (2012) 30:95-114. doi:10.1146/annurevimmunol-020711-075035

134. Moran AE, Holzapfel KL, Xing Y, Cunningham NR, Maltzman JS, Punt J, et al. T cell receptor signal strength in Treg and iNKT cell development demonstrated by a novel fluorescent reporter mouse. J Exp Med (2011) 208:1279-89. doi:10.1084/jem.20110308

135. Seiler MP, Mathew R, Liszewski MK, Spooner C, Barr K, Meng F, et al. Elevated and sustained expression of the transcription factors Egr1 and Egr2 controls NKT lineage differentiation in response to TCR signaling. Nat Immunol (2012) 13:264-71. doi:10.1038/ni.2230

136. Griewank K, Borowski C, Rietdijk S, Wang N, Julien A, Wei DG, et al. Homotypic interactions mediated by Slamf1 and Slamf6 receptors control NKT cell lineage development. Immunity (2007) 27:751-62. doi:10.1016/j. immuni.2007.08.020

137. Dutta M, Kraus ZJ, Gomez-Rodriguez J, Hwang S-H, Cannons JL, Cheng J, et al. A role for Ly108 in the induction of promyelocytic zinc finger transcription factor in developing thymocytes. J Immunol (2013) 190:2121-8. doi:10.4049/jimmunol.1202145

138. Pellicci DG, Uldrich AP, Kyparissoudis K, Crowe NY, Brooks AG, Hammond KJL, et al. Intrathymic NKT cell development is blocked by the presence of $\alpha$-galactosylceramide. Eur J Immunol (2003) 33:1816-23. doi:10.1002/eji. 200323894

139. Chun T, Page MJ, Gapin L, Matsuda JL, Xu H, Nguyen H, et al. CD1dexpressing dendritic cells but not thymic epithelial cells can mediate negative selection of NKT cells. J Exp Med (2003) 197:907-18. doi:10.1084/ jem.20021366

140. Benlagha K, Kyin T, Beavis A, Teyton L, Bendelac A. A thymic precursor to the NK T cell lineage. Science (2002) 296:553-5. doi:10.1126/science.1069017

141. Dose M, Sleckman BP, Han J, Bredemeyer AL, Bendelac A, Gounari F. Intrathymic proliferation wave essential for $\mathrm{V} \alpha 14+$ natural killer $\mathrm{T}$ cell development depends on c-Myc. Proc Natl Acad Sci U S A (2009) 106:8641-6. doi:10.1073/pnas.0812255106

142. McNab FW, Berzins SP, Pellicci DG, Kyparissoudis K, Field K, Smyth MJ. The influence of CD1d in postselection NKT cell maturation and homeostasis. J Immunol (2005) 175:3762-8. doi:10.4049/jimmunol.175.6.3762

143. Fedeli M, Napolitano A, Wong MPM, Marcais A, De Lalla C, Colucci F, et al. Dicer-dependent microRNA pathway controls invariant NKT cell development. J Immunol (2009) 183:2506-12. doi:10.4049/jimmunol.0901361

144. Park SH, Benlagha K, Lee D, Balish E, Bendelac A. Unaltered phenotype, tissue distribution and function of $\mathrm{V} \alpha 14(+)$ NKT cells in germ-free mice.
Eur J Immunol (2000) 30:620-5. doi:10.1002/1521-4141(200002)30:2<620:: AID-IMMU620>3.0.CO;2-4

145. Wei B, Wingender G, Fujiwara D, Chen DY, McPherson M, Brewer S, et al. Commensal microbiota and CD8+ T cells shape the formation of invariant NKT cells. J Immunol (2010) 184:1218-26. doi:10.4049/jimmunol. 0902620

146. Lee YJ, Starrett GJ, Lee ST, Yang R, Henzler CM, Jameson SC, et al. Lineagespecific effector signatures of invariant NKT cells are shared amongst $\gamma \delta \mathrm{T}$, innate lymphoid, and Th cells. J Immunol (2016) 197:1460-70. doi:10.4049/ jimmunol.1600643

147. Engel I, Seumois G, Chavez L, Samaniego-Castruita D, White B, Chawla A, et al. Innate-like functions of natural killer $\mathrm{T}$ cell subsets result from highly divergent gene programs. Nat Immunol (2016) 17:728-39. doi:10.1038/ ni. 3437

148. Bennstein SB. Unraveling natural killer T-cells development. Front Immunol (2017) 8:1950. doi:10.3389/fimmu.2017.01950

149. Gadue P, Stein PL. NK T cell precursors exhibit differential cytokine regulation and require Itk for efficient maturation. J Immunol (2002) 169:2397-406. doi:10.4049/jimmunol.169.5.2397

150. Pellicci DG, Hammond KJL, Uldrich AP, Baxter AG, Smyth MJ, Godfrey DI. A natural killer T (NKT) cell developmental pathway involving a thymusdependent NK1.1-CD4+ CD1d-dependent precursor stage. J Exp Med (2002) 195:835-44. doi:10.1084/jem.20011544

151. Savage AK, Constantinides MG, Bendelac A. Promyelocytic leukemia zinc finger turns on the effector $\mathrm{T}$ cell program without requirement for agonist TCR signaling. J Immunol (2011) 186:5801-6. doi:10.4049/ jimmunol.1100119

152. Raberger J, Schebesta A, Sakaguchi S, Boucheron N, Blomberg KEM, Berglöf A, et al. The transcriptional regulator PLZF induces the development of CD44 high memory phenotype T cells. Proc Natl Acad Sci U S A (2008) 105:17919-24. doi:10.1073/pnas.0805733105

153. Kovalovsky D, Alonzo ES, Uche OU, Eidson M, Nichols KE, Sant'Angelo DB. PLZF induces the spontaneous acquisition of memory/effector functions in T cells independently of NKT cell-related signals. J Immunol (2010) 184:6746-55. doi:10.4049/jimmunol.1000776

154. Mao A-P, Ishizuka IE, Kasal DN, Mandal M, Bendelac A. A shared Runx1bound Zbtb16 enhancer directs innate and innate-like lymphoid lineage development. Nat Commun (2017) 8:863. doi:10.1038/s41467-017-00882-0

155. Leeansyah E, Loh L, Nixon DF, Sandberg JK. Acquisition of innate-like microbial reactivity in mucosal tissues during human fetal MAIT-cell development. Nat Commun (2014) 5:3143. doi:10.1038/ncomms4143

156. Sandberg JK, Stoddart CA, Brilot F, Jordan KA, Nixon DF. Development of innate CD4+ $\alpha$-chain variable gene segment $24(\mathrm{~V} \alpha 24)$ natural killer T cells in the early human fetal thymus is regulated by IL-7. Proc Natl Acad Sci U S A (2004) 101:7058-63. doi:10.1073/pnas.0305986101

157. Bienemann K, Iouannidou K, Schoenberg K, Krux F, Reuther S, Feyen O, et al. iNKT cell frequency in peripheral blood of Caucasian children and adolescent: the absolute iNKT cell count is stable from birth to adulthood. Scand J Immunol (2011) 74:406-11. doi:10.1111/j.1365-3083.2011.02591.x

158. Berzins SP, Cochrane AD, Pellicci DG, Smyth MJ, Godfrey DI. Limited correlation between human thymus and blood NKT cell content revealed by an ontogeny study of paired tissue samples. Eur J Immunol (2005) 35:1399-407. doi:10.1002/eji.200425958

159. Paquin-Proulx D, Santos BAN, Barsotti NS, Marinho AKBB, Kokron CM, Carvalho KI, et al. Loss of circulating mucosal-associated invariant $\mathrm{T}$ cells in common variable immunodeficiency is associated with immune activation and loss of Eomes and PLZF. ImmunoHorizons (2017) 1:142-55. doi:10.4049/ immunohorizons. 1700039

160. Bosma A, Abdel-Gadir A, Isenberg DA, Jury EC, Mauri C. Lipid-antigen presentation by CD1d+ B cells is essential for the maintenance of invariant natural killer T cells. Immunity (2012) 36:477-90. doi:10.1016/j.immuni.2012. 02.008

161. Kurioka A, Ussher JE, Cosgrove C, Clough C, Fergusson JR, Smith K, et al. MAIT cells are licensed through granzyme exchange to kill bacterially sensitized targets. Mucosal Immunol (2015) 8:429-40. doi:10.1038/mi.2014.81

162. Gold MC, McLaren JE, ReistetterJA, Smyk-Pearson S, Ladell K, Swarbrick GM, et al. MR1-restricted MAIT cells display ligand discrimination and pathogen selectivity through distinct $\mathrm{T}$ cell receptor usage. JExp Med (2014) 211:1601-10. doi:10.1084/jem.20140507 
163. Howson LJ, Napolitani G, Shepherd D, Ghadbane H, Kurupati P, PreciadoLlanes L, et al. MAIT cell clonal expansion and TCR repertoire shaping in human volunteers challenged with Salmonella Paratyphi A. Nat Commun (2018) 9:303. doi:10.1038/s41467-017-02540-x

164. Eger KA, Sundrud MS, Motsinger AA, Tseng M, Van Kaer L, Unutmaz D. Human natural killer $\mathrm{T}$ cells are heterogeneous in their capacity to reprogram their effector functions. PLoS One (2006) 1:e50. doi:10.1371/journal. pone. 0000050

165. Surh CD, Sprent J. Homeostasis of naive and memory T cells. Immunity (2008) 29:848-62. doi:10.1016/j.immuni.2008.11.002

166. Matsuda JL, Gapin L, Sidobre S, Kieper WC, Tan JT, Ceredig R, et al. Homeostasis of V $\alpha 14$ i NKT cells. Nat Immunol (2002) 3:966-74. doi:10.1038/ ni837

167. Sattler A, Dang-Heine C, Reinke P, Babel N. IL-15 dependent induction of IL-18 secretion as a feedback mechanism controlling human MAIT-cell effector functions. Eur J Immunol (2015) 45:2286-98. doi:10.1002/eji.201445313

168. van Wilgenburg B, Scherwitzl I, Hutchinson EC, Leng T, Kurioka A, Kulicke C, et al. MAIT cells are activated during human viral infections. Nat Commun (2016) 7:11653. doi:10.1038/ncomms11653

169. Tang X-Z, Jo J, Tan AT, Sandalova E, Chia A, Tan KC, et al. IL-7 licenses activation of human liver intrasinusoidal mucosal-associated invariant $\mathrm{T}$ cells. J Immunol (2013) 190:3142-52. doi:10.4049/jimmunol.1203218

170. Wei DG, Lee H, Park S-H, Beaudoin L, Teyton L, Lehuen A, et al. Expansion and long-range differentiation of the NKT cell lineage in mice expressing CD1d exclusively on cortical thymocytes. JExp Med (2005) 202:239-48. doi:10.1084/jem.20050413

171. Kojo S, Adachi Y, Keino H, Taniguchi M, Sumida T. Dysfunction of T cell receptor AV24AJ18+,BV11+ double-negative regulatory natural killer T cells in autoimmune diseases. Arthritis Rheum (2001) 44:1127-38. doi:10.1002/ 1529-0131(200105)44:5<1127::AID-ANR194>3.0.CO;2-W

172. van der Vliet HJJ, Blomberg von BME, Nishi N, Reijm M, Voskuyl AE, van Bodegraven AA, et al. Circulating V $\alpha 24+\mathrm{V} \beta 11+$ NKT cell numbers are decreased in a wide variety of diseases that are characterized by autoreactive tissue damage. Clin Immunol (2001) 100:144-8. doi:10.1006/clim.2001. 5060

173. Hashimoto K, Hirai M, Kurosawa Y. A gene outside the human MHC related to classical HLA class I genes. Science (1995) 269:693-5. doi:10.1126/ science. 7624800

174. Riegert P, Wanner V, Bahram S. Genomics, isoforms, expression, and phylogeny of the MHC class I-related MR1 gene. J Immunol (1998) 161:4066-77.

175. McWilliam HEG, Eckle SBG, Theodossis A, Liu L, Chen Z, Wubben JM, et al. The intracellular pathway for the presentation of vitamin B-related antigens by the antigen-presenting molecule MR1. Nat Immunol (2016) 17:531-7. doi:10.1038/ni.3416

176. Brigl M, Brenner MB. CD1: antigen presentation and T cell function. Annu Rev Immunol (2004) 22:817-90. doi:10.1146/annurev.immunol.22.012703. 104608

177. Bendelac A, Killeen N, Littman DR, Schwartz RH. A subset of CD4+ thymocytes selected by MHC class I molecules. Science (1994) 263:1774-8. doi:10.1126/science.7907820

178. Ladd M, Sharma A, Huang Q, Wang AY, Xu L, Genowati I, et al. Natural killer $\mathrm{T}$ cells constitutively expressing the interleukin-2 receptor $\alpha$ chain early in life are primed to respond to lower antigenic stimulation. Immunology (2010) 131:289-99. doi:10.1111/j.1365-2567.2010.03304.x

179. Kita H, Naidenko OV, Kronenberg M, Ansari AA, Rogers P, He XS, et al. Quantitation and phenotypic analysis of natural killer T cells in primary biliary cirrhosis using a human CD1d tetramer. Gastroenterology (2002) 123:1031-43. doi:10.1053/gast.2002.36020

180. Kenna T, Mason LG, Porcelli SA, Koezuka Y, Hegarty JE, O’Farrelly C, et al. NKT cells from normal and tumor-bearing human livers are phenotypically and functionally distinct from murine NKT cells. J Immunol (2003) 171:1775-9. doi:10.4049/jimmunol.171.10.5631

181. Wingender G, Stepniak D, Krebs P, Lin L, McBride S, Wei B, et al. Intestinal microbes affect phenotypes and functions of invariant natural killer $\mathrm{T}$ cells in mice. Gastroenterology (2012) 143:418-28. doi:10.1053/j.gastro.2012.04.017

182. Perez-Muñoz ME, Arrieta M-C, Ramer-Tait AE, Walter J. A critical assessment of the "sterile womb" and "in utero colonization" hypotheses: implications for research on the pioneer infant microbiome. Microbiome (2017) 5:48. doi:10.1186/s40168-017-0268-4
183. Loh L, Wang Z, Sant S, Koutsakos M, Jegaskanda S, Corbett AJ, et al. Human mucosal-associated invariant $\mathrm{T}$ cells contribute to antiviral influenza immunity via IL-18-dependent activation. Proc Natl Acad Sci U S A (2016) 113:10133-8. doi:10.1073/pnas.1610750113

184. Paquin-Proulx D, Avelino-Silva VI, Santos BAN, Silveira Barsotti N, Siroma F, Fernandes Ramos J, et al. MAIT cells are activated in acute dengue virus infection and after in vitro Zika virus infection. PLoS Negl Trop Dis (2018) 12:e006154. doi:10.1371/journal.pntd.0006154

185. van Wilgenburg B, Loh L, Chen Z, Pediongco TJ, Wang H, Shi M, et al. MAIT cells contribute to protection against lethal influenza infection in vivo. bioRxiv (2018). doi:10.1101/247205

186. Fox LM, Cox DG, Lockridge JL, Wang X, Chen X, Scharf L, et al. Recognition of lyso-phospholipids by human natural killer T lymphocytes. PLoS Biol (2009) 7:e1000228. doi:10.1371/journal.pbio.1000228

187. FacciottiF,Ramanjaneyulu GS,LeporeM,SansanoS,CavallariM,KistowskaM, et al. Peroxisome-derived lipids are self antigens that stimulate invariant natural killer T cells in the thymus. Nat Immunol (2012) 13:474-80. doi:10.1038/ ni.2245

188. Kain L, Webb B, Anderson BL, Deng S, Holt M, Costanzo A, et al. The identification of the endogenous ligands of natural killer $\mathrm{T}$ cells reveals the presence of mammalian $\alpha$-linked glycosylceramides. Immunity (2014) 41:543-54. doi:10.1016/j.immuni.2014.08.017

189. Leite-De-Moraes MC, Hameg A, Arnould A, Machavoine F, Koezuka Y, Schneider E, et al. A distinct IL-18-induced pathway to fully activate NK $\mathrm{T}$ lymphocytes independently from TCR engagement. JImmunol (1999) 163:5871-6.

190. Nagarajan NA, Kronenberg M. Invariant NKT cells amplify the innate immune response to lipopolysaccharide. J Immunol (2007) 178:2706-13. doi:10.4049/jimmunol.178.5.2706

191. Wesley JD, Tessmer MS, Chaukos D, Brossay L. NK cell-like behavior of Vo14i NK T cells during MCMV infection. PLoS Pathog (2008) 4:e1000106. doi:10.1371/journal.ppat.1000106

192. Tyznik AJ, Tupin E, Nagarajan NA, Her MJ, Benedict CA, Kronenberg M. Cutting edge: the mechanism of invariant NKT cell responses to viral danger signals. J Immunol (2008) 181:4452-6. doi:10.4049/jimmunol.181.7.4452

193. Ussher JE, Bilton M, Attwod E, Shadwell J, Richardson R, de Lara C, et al. CD161++ CD8+ T cells, including the MAIT cell subset, are specifically activated by IL-12+IL-18 in a TCR-independent manner. Eur J Immunol (2014) 44:195-203. doi:10.1002/eji.201343509

194. Holzapfel KL, Tyznik AJ, Kronenberg M, Hogquist KA. Antigen-dependent versus -independent activation of invariant NKT cells during infection. J Immunol (2014) 192:5490-8. doi:10.4049/jimmunol.1400722

195. Jo J, Tan AT, Ussher JE, Sandalova E, Tang X-Z, Tan-Garcia A, et al. Toll-like receptor 8 agonist and bacteria trigger potent activation of innate immune cells in human liver. PLoS Pathog (2014) 10:e1004210. doi:10.1371/journal. ppat. 1004210

196. Wallington JC, Williams AP, Staples KJ, Wilkinson TMA. IL-12 and IL-7 synergize to control mucosal-associated invariant T-cell cytotoxic responses to bacterial infection. JAllergy Clin Immunol (2018) 141:2182-95.e6. doi:10.1016/j.jaci.2017.08.009

197. Brigl M, Bry L, Kent SC, Gumperz JE, Brenner MB. Mechanism of CD1drestricted natural killer $\mathrm{T}$ cell activation during microbial infection. Nat Immunol (2003) 4:1230-7. doi:10.1038/ni1002

198. Salio M, Speak AO, Shepherd D, Polzella P, Illarionov PA, Veerapen N, et al. Modulation of human natural killer T cell ligands on TLR-mediated antigen-presenting cell activation. Proc Natl Acad Sci U S A (2007) 104:20490-5. doi:10.1073/pnas.0710145104

199. Paget C, Mallevaey T, Speak AO, Torres D, Fontaine J, Sheehan KCF, et al. Activation of invariant NKT cells by toll-like receptor 9-stimulated dendritic cells requires type I interferon and charged glycosphingolipids. Immunity (2007) 27:597-609. doi:10.1016/j.immuni.2007.08.017

200. Mattner J, Debord KL, Ismail N, Goff RD, Cantu C, Zhou D, et al. Exogenous and endogenous glycolipid antigens activate NKT cells during microbial infections. Nature (2005) 434:525-9. doi:10.1038/nature03408

201. Kurioka A, van Wilgenburg B, Javan RR, Hoyle R, van Tonder AJ, Harrold CL, et al. Diverse Streptococcus pneumoniae strains drive a mucosal-associated invariant T-cell response through major histocompatibility complex class I-related molecule-dependent and cytokine-driven pathways. J Infect Dis (2018) 217:988-99. doi:10.1093/infdis/jix647 
202. Kuylenstierna C, Björkström NK, Andersson SK, Sahlström P, Bosnjak L, Paquin-Proulx D, et al. NKG2D performs two functions in invariant NKT cells: direct TCR-independent activation of NK-like cytolysis and co-stimulation of activation by CD1d. Eur J Immunol (2011) 41:1913-23. doi:10.1002/eji.200940278

203. Arase $\mathrm{H}$, Arase N, Saito T. Interferon $\gamma$ production by natural killer (NK) cells and NK1.1+ T cells upon NKR-P1 cross-linking. J Exp Med (1996) 183:2391-6. doi:10.1084/jem.183.5.2391

204. Le Bourhis L, Dusseaux M, Bohineust A, Bessoles S, Martin E, Premel V, et al. MAIT cells detect and efficiently lyse bacterially-infected epithelial cells. PLoS Pathog (2013) 9:e1003681. doi:10.1371/journal.ppat.1003681

205. Exley M, Porcelli S, Furman M, Garcia J, Balk S. CD161 (NKR-P1A) costimulation of CD1d-dependent activation of human $\mathrm{T}$ cells expressing invariant V $\alpha 24 \mathrm{~J} \alpha \mathrm{Q} \mathrm{T}$ cell receptor $\alpha$ chains. J Exp Med (1998) 188:867-76. doi:10.1084/jem.188.5.867

206. van den Heuvel MJ, Garg N, Van Kaer L, Haeryfar SMM. NKT cell costimulation: experimental progress and therapeutic promise. Trends Mol Med (2011) 17:65-77. doi:10.1016/j.molmed.2010.10.007

207. Singh AK, Gaur P, Das SN. Natural killer T cell anergy, co-stimulatory molecules and immunotherapeutic interventions. Hum Immunol (2014) 75:250-60. doi:10.1016/j.humimm.2013.12.004

208. Pal E, Tabira T, Kawano T, Taniguchi M, Miyake S, Yamamura T. Costimulation-dependent modulation of experimental autoimmune encephalomyelitis by ligand stimulation of V $\alpha 14 \mathrm{NK}$ T cells. J Immunol (2001) 166:662-8. doi:10.4049/jimmunol.166.1.662

209. Dias J, Leeansyah E, Sandberg JK. Multiple layers of heterogeneity and subset diversity in human MAIT cell responses to distinct microorganisms and to innate cytokines. Proc Natl Acad Sci U S A (2017) 114(27):E5434-43. doi:10.1073/pnas.1705759114

210. Shaler CR, Choi J, Rudak PT, Memarnejadian A, Szabo PA, Tun-Abraham ME, et al. MAIT cells launch a rapid, robust and distinct hyperinflammatory response to bacterial superantigens and quickly acquire an anergic phenotype that impedes their cognate antimicrobial function: defining a novel mechanism of superantigen-induced immunopathology and immunosuppression. PLoS Biol (2017) 15:e2001930. doi:10.1371/journal.pbio. 2001930

211. Jiang J, Wang X, An H, Yang B, Cao Z, Liu Y, et al. MAIT cell function is modulated by PD-1 signaling in patients with active tuberculosis. Am J Respir Crit Care Med (2014) 190(3):329-39. doi:10.1164/rccm.2014010106OC

212. Jiang J, Cao Z, Shan W, Liu H, Cheng X. 4-1BB expression on MAIT cells is associated with enhanced IFN- $\gamma$ production and depends on IL-2. Cell Immunol (2018) 328:58-69. doi:10.1016/j.cellimm.2018.03.013

213. Hengst J, Strunz B, Deterding K, Ljunggren H-G, Leeansyah E, Manns MP, et al. Nonreversible MAIT cell-dysfunction in chronic hepatitis C virus infection despite successful interferon-free therapy. Eur J Immunol (2016) 46:2204-10. doi:10.1002/eji.201646447

214. Patel O, Kjer-Nielsen L, Le Nours JEROM, Eckle SBG, Birkinshaw R, Beddoe T, et al. Recognition of vitamin B metabolites by mucosal-associated invariant T cells. Nat Commun (2013) 4:1-9. doi:10.1038/ncomms3142

215. Gérart S, Sibéril S, Martin E, Lenoir C, Aguilar C, Picard C, et al. Human iNKT and MAIT cells exhibit a PLZF-dependent proapoptotic propensity that is counterbalanced by XIAP. Blood (2013) 121:614-23. doi:10.1182/ blood-2012-09-456095

216. Savla R, Browne J, Plassat V, Wasan KM, Wasan EK. Review and analysis of FDA approved drugs using lipid-based formulations. Drug Dev Ind Pharm (2017) 43:1743-58. doi:10.1080/03639045.2017.1342654

217. Brigl M, Brenner MB. How invariant natural killer T cells respond to infection by recognizing microbial or endogenous lipid antigens. Semin Immunol (2010) 22:79-86. doi:10.1016/j.smim.2009.10.006

218. Venkataswamy MM, Porcelli SA. Lipid and glycolipid antigens of CD1d-restricted natural killer T cells. Semin Immunol (2010) 22:68-78. doi:10.1016/j.smim.2009.10.003

219. Birkholz AM, Howell AR, Kronenberg M. The alpha and omega of galactosylceramides in T cell immune function. J Biol Chem (2015) 290:15365-70. doi:10.1074/jbc.R115.647057

220. Hung J-T, Huang J-R, Yu AL. Tailored design of NKT-stimulatory glycolipids for polarization of immune responses. J Biomed Sci (2017) 24:22. doi:10.1186/ s12929-017-0325-0
221. Lynch L, Michelet X, Zhang S, Brennan PJ, Moseman A, Lester C, et al. Regulatory iNKT cells lack expression of the transcription factor PLZF and control the homeostasis of Treg cells and macrophages in adipose tissue. Nat Immunol (2015) 16:85-95. doi:10.1038/ni.3047

222. Wingender G, Krebs P, Beutler B, Kronenberg M. Antigen-specific cytotoxicity by invariant NKT cells in vivo is CD95/CD178-dependent and is correlated with antigenic potency. J Immunol (2010) 185:2721-9. doi:10.4049/ jimmunol.1001018

223. Hou R, Goloubeva O, Neuberg DS, Strominger JL, Wilson SB. Interleukin-12 and interleukin-2-induced invariant natural killer T-cell cytokine secretion and perforin expression independent of T-cell receptor activation. Immunology (2003) 110:30-7. doi:10.1046/j.1365-2567.2003.01701.x

224. O’Reilly V, Zeng SG, Bricard G, Atzberger A, Hogan AE, Jackson J, et al. Distinct and overlapping effector functions of expanded human CD4+, CD8 $\alpha+$ and CD4-CD8 $\alpha$ - invariant natural killer T cells. PLoS One (2011) 6:e28648. doi:10.1371/journal.pone.0028648

225. Salio M, Gasser O, Gonzalez-Lopez C, Martens A, Veerapen N, Gileadi U, et al. Activation of human mucosal-associated invariant $\mathrm{T}$ cells induces CD40L-dependent maturation of monocyte-derived and primary dendritic cells. J Immunol (2017) 199(8):2631-8. doi:10.4049/jimmunol.1700615

226. Meierovics AI, Cowley SC. MAIT cells promote inflammatory monocyte differentiation into dendritic cells during pulmonary intracellular infection. J Exp Med (2016) 213:2793-809. doi:10.1084/jem.20160637

227. Bennett MS, Trivedi S, Iyer AS, Hale JS, Leung DT. Human mucosal-associated invariant T (MAIT) cells possess capacity for B-cell help. J Leukoc Biol (2017) 102(5):1261-9. doi:10.1189/jlb.4A0317-116R

228. Hegde S, Chen X, Keaton JM, Reddington F, Besra GS, Gumperz JE. NKT cells direct monocytes into a DC differentiation pathway. J Leukoc Biol (2007) 81:1224-35. doi:10.1189/jlb.1206718

229. Kitamura H, Iwakabe K, Yahata T, Nishimura S-I, Ohta A, Ohmi Y, et al. The natural killer $\mathrm{T}(\mathrm{NKT})$ cell ligand $\alpha$-galactosylceramide demonstrates its immunopotentiating effect by inducing interleukin (IL)-12 production by dendritic cells and IL-12 receptor expression on NKT cells. J Exp Med (1999) 189:1121-8. doi:10.1084/jem.189.7.1121

230. Carnaud C, Lee D, Donnars O, Park SH, Beavis A, Koezuka Y, et al. Cutting edge: cross-talk between cells of the innate immune system: NKT cells rapidly activate NK cells. J Immunol (1999) 163:4647-50.

231. Fujii S-I, Shimizu K, Smith C, Bonifaz L, Steinman RM. Activation of natural killer T cells by $\alpha$-galactosylceramide rapidly induces the full maturation of dendritic cells in vivo and thereby acts as an adjuvant for combined CD4 and CD8 T cell immunity to a coadministered protein. J Exp Med (2003) 198:267-79. doi:10.1084/jem.20030324

232. Hermans IF, Silk JD, Gileadi U, Salio M, Mathew B, Ritter G, et al. NKT cells enhance $\mathrm{CD} 4+$ and $\mathrm{CD} 8+\mathrm{T}$ cell responses to soluble antigen in vivo through direct interaction with dendritic cells. J Immunol (2003) 171:5140-7. doi:10.4049/jimmunol.171.10.5140

233. Dellabona P, Abrignani S, Casorati G. iNKT-cell help to B cells: a cooperative job between innate and adaptive immune responses. Eur J Immunol (2014) 44:2230-7. doi:10.1002/eji.201344399

234. King IL, Fortier A, Tighe M, Dibble J, Watts GFM, Veerapen N, et al. Invariant natural killer $\mathrm{T}$ cells direct $\mathrm{B}$ cell responses to cognate lipid antigen in an IL-21-dependent manner. Nat Immunol (2011) 13:44-50. doi:10.1038/ ni. 2172

235. Kurioka A, Jahun AS, Hannaway RF, Walker LJ, Fergusson JR, SverremarkEkström E, et al. Shared and distinct phenotypes and functions of human CD161++ V $\alpha 7.2+$ T cell subsets. Front Immunol (2017) 8:1031. doi:10.3389/ fimmu.2017.01031

236. Kim CH, Butcher EC, Johnston B. Distinct subsets of human Vo24-invariant NKT cells: cytokine responses and chemokine receptor expression. Trends Immunol (2002) 23:516-9. doi:10.1016/S1471-4906(02)02323-2

237. Lin H, Nieda M, Hutton JF, Rozenkov V, Nicol AJ. Comparative gene expression analysis of NKT cell subpopulations. J Leukoc Biol (2006) 80:164-73. doi:10.1189/jlb.0705421

238. Lin H, Nieda M, Rozenkov V, Nicol AJ. Analysis of the effect of different NKT cell subpopulations on the activation of CD4 and CD8 T cells, NK cells, and B cells. Exp Hematol (2006) 34:289-95. doi:10.1016/j.exphem.2005. 12.008

239. Zeng SG, Ghnewa YG, O'Reilly VP, Lyons VG, Atzberger A, Hogan AE, et al. Human invariant NKT cell subsets differentially promote differentiation, 
antibody production, and T cell stimulation by B cells in vitro. J Immunol (2013) 191:1666-76. doi:10.4049/jimmunol.1202223

240. Liu T-Y, Uemura Y, Suzuki M, Narita Y, Hirata S, Ohyama H, et al. Distinct subsets of human invariant NKT cells differentially regulate $\mathrm{T}$ helper responses via dendritic cells. Eur J Immunol (2008) 38:1012-23. doi:10.1002/ eji.200737838

241. Constantinides MG, Bendelac A. Transcriptional regulation of the NKT cell lineage. Curr Opin Immunol (2013) 25:161-7. doi:10.1016/j. coi.2013.01.003

242. Georgiev H, Ravens I, Benarafa C, Förster R, Bernhardt G. Distinct gene expression patterns correlate with developmental and functional traits of iNKT subsets. Nat Commun (2016) 7:13116. doi:10.1038/ncomms13116

243. Cameron G, Godfrey DI. Differential surface phenotype and context-dependent reactivity of functionally diverse NKT cells. Immunol Cell Biol (2018). doi:10.1111/imcb.12034

244. Gordy LE, Bezbradica JS, Flyak AI, Spencer CT, Dunkle A, Sun J, et al. IL-15 regulates homeostasis and terminal maturation of NKT cells. J Immunol (2011) 187:6335-45. doi:10.4049/jimmunol.1003965
245. Wong EB, Ndung'u T, Kasprowicz VO. The role of mucosal-associated invariant $\mathrm{T}$ cells in infectious diseases. Immunology (2017) 150:45-54. doi:10.1111/imm.12673

246. Carreño LJ, Saavedra-Ávila NA, Porcelli SA. Synthetic glycolipid activators of natural killer T cells as immunotherapeutic agents. Clin Transl Immunology (2016) 5:e69. doi:10.1038/cti.2016.14

Conflict of Interest Statement: The authors declare that the research was conducted in the absence of any commercial or financial relationships that could be construed as a potential conflict of interest.

Copyright $\odot 2018$ Garner, Klenerman and Provine. This is an open-access article distributed under the terms of the Creative Commons Attribution License (CC BY). The use, distribution or reproduction in other forums is permitted, provided the original author(s) and the copyright owner are credited and that the original publication in this journal is cited, in accordance with accepted academic practice. No use, distribution or reproduction is permitted which does not comply with these terms. 